To be published in Proc. of the Symp. on Nuclear Data Evaluation Methodology, October 1992, Brookhaven National Lab.

$$
\begin{aligned}
& \text { DOE/ER/40610-.T3 } \\
& \text { CONF- } 9210303-1
\end{aligned}
$$

\title{
THE DATA BASE OF THE STANDARDS AND RELATED CROSS SECTIONS
} AFTER ENDF/B-VI

$$
\text { AI05-9/ER 406/O-T3 }
$$

\author{
W. P. Poenitz \\ Argonne National Laboratory - West \\ P. O. Box 2528 \\ Idaho Falls, Idaho 83403-2528
}

and

A. D. Carlson

National Institute of Standards and Technology

Radiation Physics Building

Washington, DC 20234

\begin{abstract}
A brief description is given of the procedure used in the global evaluation of the standards and other important cross sections for ENDF/B-VI. The standards involved were ${ }^{6} \mathrm{Li}(\mathrm{n}, \mathrm{t}),{ }^{10} \mathrm{~B}\left(\mathrm{n}, \alpha_{0}\right),{ }^{10} \mathrm{~B}\left(\mathrm{n}, \alpha_{1}\right),{ }^{197} \mathrm{Au}(\mathrm{n}, \gamma)$, and ${ }^{235} \mathrm{U}(\mathrm{n}, \mathrm{f})$. Other standards evaluated independently were $\mathrm{H}(n, p),{ }^{3} \mathrm{He}(n, p), \mathrm{C}(\mathrm{n}, \mathrm{n})$. The other cross sections involved were ${ }^{236} \mathrm{U}(\mathrm{n}, \gamma),{ }^{238} \mathrm{U}(\mathrm{n}, \mathrm{f})$, and ${ }^{239} \mathrm{Pu}(\mathrm{n}, \mathrm{f})$. The results of the evaluation are compared with new or revised experimental data which have become available after the completion of ENDF/B-VI. Overall good agreement is found, but a few problems are indicated by the new data.
\end{abstract}

\section{DISCLAIMER}

This report was prepared as an account of work sponsored by an agency of the United States Government. Neither the United States Government nor any agency thereof, nor any of their employees, makes any warranty, express or implied, or assumes any legal liability or responsibility for the accuracy, completeness, or usefulness of any information, apparatus, product, or process disclosed, or represents that its use would not infringe privately owned rights. Reference herein to any specific commercial product, process, or service by trade name, trademark, manufacturer, or otherwise does not necessarily constitute or imply its endorsement, recommendation, or favoring by the United States Government or any agency thereof. The views and opinions of authors expressed herein do not necessarily state or reflect those of the United States Government or any agency thereof.

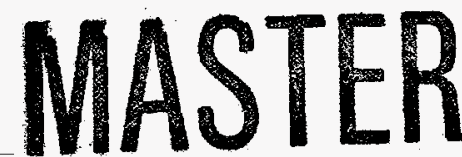




\section{DISCLAMMER}

Portions of this document may be illegible in electronic image products. Images are produced from the best available original document. 


\section{Introduction}

Measurements of neutron interaction cross sections have been carried out most often relative to a few other neutron interaction cross sections, called standards, which were assumed to be well known. The advantage of such a procedure is that an absolute neutron fluence measurement is not required. The choice of these reference or "standard" cross sections was mostly determined by practicality, e.g., smooth energy dependence and large size of the cross section were desirable; it should be possible to easily implement the reaction in suitable detectors; etc. In Table 1a the cross sections are listed which have been declared "standards" by one committee or another since they are frequently used reference cross sections. Some other reference cross sections and data which are occasionally used are listed in Table 1b. The neutron spectrum of the spontaneously fissioning ${ }^{252} \mathrm{Cf}$ is used as a neutron spectrum standard. It is used for the calibration of neutron detectors which, in turn, can be used for cross section measurements. The number of neutrons emitted per fission ( $\bar{\nu})$ of ${ }^{252} \mathrm{Cf}$ has been used as the standard for the measurements of $\bar{\nu}(E)$ for fissile and fertile nuclei.

Absolute values of the standard cross sections have been measured involving in most cases absolute neutron fluence determinations. An exception is the hydrogen scattering cross section which can be determined as a total cross section in transmission measurements and thus does not require absolute fluence measurements. As a consequence, this cross section is quite well known (uncertainties of less than $0.5 \%$ ). However, the angular distribution for neutron scattering from hydrogen, which is used in some detectors for neutron fluence measurements, is less well known. The detection efficiency for the recoil protons and other aspects of the cross section measurement introduce additional uncertainties with the result that cross sections measured relative to the hydrogen scattering cross section display discrepancies similar to those which involved absolute neutron fluence determinations. Discrepancies among absolute measurements of standard cross sections were substantial ( $\approx$ a factor of 2 ) for older data. Figure 1, for example, gives the impression that one is viewing a section of the Milky Way, however it shows the capture cross section data for gold which were available in 1966 . The agreement among different measurements of the standard cross sections has improved substantially in the past 25 years, but some discrepancies in the $5-10 \%$ range persisted for a long time.

Evaluations of the existing data prior to ENDF/B-VI often were artistic in nature instead of being based on scientific procedures. The evaluations generally involved drawing a curve through the existing data. Curves were drawn which emphasized certain data sets which were perceived to be "better" than others, or because they were the result of the most recent measurements. These evaluation procedures were in part chosen in response to the poor data base. The evaluations up to version VI 
Table 1. Standards and Other Cross Sections and Data Involved in the ENDF/B-VI Global Evaluation

\begin{tabular}{|c|c|c|c|c|}
\hline & $\begin{array}{l}\text { Cross Section or } \\
\text { Data }\end{array}$ & $\begin{array}{l}\text { Energy Range of } \\
\text { Standard }\end{array}$ & $\begin{array}{l}\text { Energy Range of Global } \\
\text { Eval. }\end{array}$ & Involvement in Global Evaluation \\
\hline \multirow[t]{7}{*}{ a } & $H(n, p)$ & $\mathrm{E} \leq 20 \mathrm{MeV}$ & -- & Independent Eval. for ENDF/B-VI'. \\
\hline & ${ }^{3} \mathrm{He}(\mathrm{n}, \mathrm{p})$ & $\mathrm{E} \leq 50 \mathrm{KeV}$ & --- & Independent Eval. for ENDF/B-VI' \\
\hline & $C(n, n)$ & $\mathrm{E} \leq 1.8 \mathrm{MeV}$ & --- & $\begin{array}{l}\text { Independent Eval. for ENDF/B-VI' } \\
\text { Scattering Standard. }\end{array}$ \\
\hline & ${ }^{6} \mathrm{Li}(\mathrm{n}, \mathrm{t})$ & $\mathrm{E} \leq 1 \mathrm{MeV}$ & $\mathrm{E} \leq 2.8 \mathrm{MeV}$ & $\begin{array}{l}\text { Flux Measurement Standard. }{ }^{6} \mathrm{Lj}(\mathrm{n}, \mathrm{n}) \text { also } \\
\text { Included in Evaluation. }\end{array}$ \\
\hline & $\begin{array}{l}{ }^{10} \mathrm{~B}(\mathrm{n}, \alpha \gamma) \\
----\cdots \\
{ }^{10} \mathrm{~B}(\mathrm{n}, \alpha)\end{array}$ & $\mathrm{E} \leq 250 \mathrm{keV}$ & $\mathrm{E} \leq 1.0 \mathrm{MeV}$ & $\begin{array}{l}\text { Flux Measurement Standard. }{ }^{10} \mathrm{~B}\left(\mathrm{n}, \alpha_{0}\right) \text {, } \\
{ }^{10} \mathrm{~B}\left(\mathrm{n}, \alpha_{1}\right),{ }^{10} \mathrm{~B}(\mathrm{n}, \mathrm{n}) \text { were Involved in the } \\
\text { Evaluation. }\end{array}$ \\
\hline & ${ }^{199} \mathrm{Au}(\mathrm{n}, \gamma)$ & $0.2 \leq \mathrm{E} \leq 2.5 \mathrm{MeV}$ & $\mathrm{E} \leq 2.8 \mathrm{MeV}$ & $\begin{array}{l}\text { Capture Cross Section Standard. } \\
{ }^{238} \mathrm{U}(\mathrm{n}, \gamma) \text { was also Included in the Global } \\
\text { Evaluation. }\end{array}$ \\
\hline & ${ }^{235} U(n, f)$ & $0.15 \mathrm{MeV} \leq 20 \mathrm{MeV}$ & $\mathrm{E} \leq 20 \mathrm{MeV}$ & $\begin{array}{l}\text { General Standard Cross Section. } \\
{ }^{239} \mathrm{Pu}(\mathrm{n}, \mathrm{f}) \text { also Included in Global Evaluation. }\end{array}$ \\
\hline \multirow[t]{2}{*}{ b } & ${ }^{238} \mathrm{U}(\mathrm{n}, \mathrm{f})$ & --- & $1 \mathrm{MeV} \leq \mathrm{E} \leq 20 \mathrm{MeV}$ & Used as Reference for $\mathrm{E}>2 \mathrm{MeV}$ \\
\hline & ${ }^{252} \mathrm{Cf}$ Spectrum, $\bar{\nu}$ & $\begin{array}{l}\text { All energies of the } \\
\text { spontaneous fission } \\
\text { spectrum }\end{array}$ & $-\cdots$ & $\begin{array}{l}\text { Independent Evaluation. } \bar{\nu} \text { was Together } \\
\text { with the Thermal Parameters Included in the } \\
\text { Global Evaluation. }\end{array}$ \\
\hline
\end{tabular}




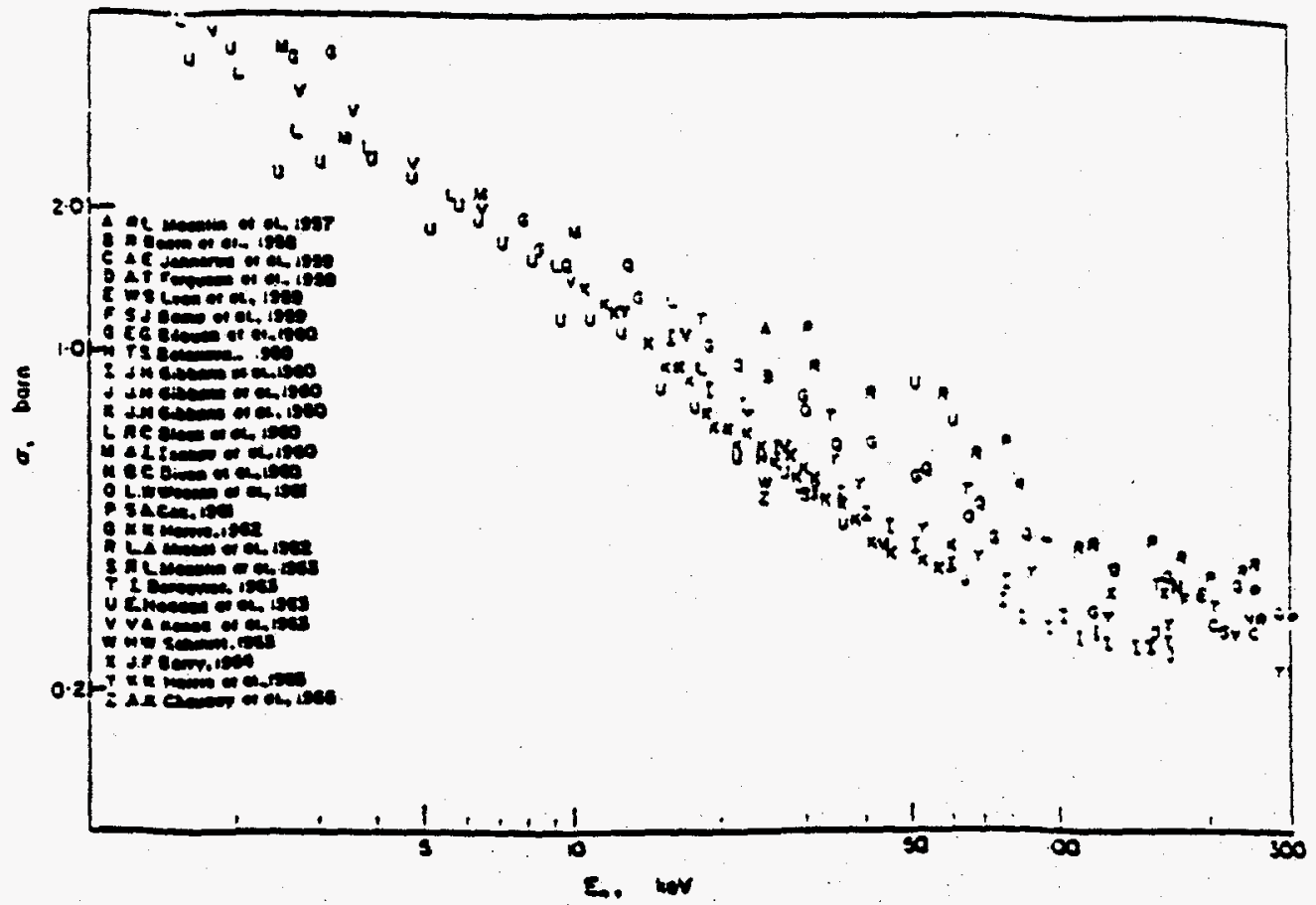

Fig. 1 Capture Cross Section Data of ${ }^{197} \mathrm{Au}(\mathrm{n}, \gamma)$ Available in 1966 (For References see Ref. 4) 
were hierarchical, i.e., $H(n, p)$ was chosen first, then ${ }^{6} \mathrm{Li}(\mathrm{n}, \mathrm{t})$ was evaluated, then ${ }^{10} \mathrm{~B}(\mathrm{n}, \alpha)$, followed by ${ }^{235} \mathrm{U}(\mathrm{n}, \mathrm{f})$, and ${ }^{197} \mathrm{Au}(\mathrm{n}, \gamma)$. There is no reason why a ratio measurement, e.g., involving the ${ }^{6} \mathrm{Li}(\mathrm{n}, \mathrm{t})$ and ${ }^{235} \mathrm{U}(\mathrm{n}, \mathrm{f})$ cross sections, should be used to derive ${ }^{235} \mathrm{U}(\mathrm{n}, \mathrm{f})$ cross sections instead of the other way around. A proper evaluation should permit ratio measurements to have an impact on each of the standard cross sections in the ratio. At the First Conference on Nuclear Data Evaluation Methods and Procedures, held at Brookhaven National Laboratory in September 1980, it was demonstrated that a simultaneous evaluation of interrelated standard cross sections by generalized least-squares was feasible ${ }^{5}$. After development of a formulation which permitted the inclusion of the R-matrix evaluations of the light elements, the Standards Subcommittee of the Cross Section Evaluation Working Group (CSEWG) decided to perform the evaluation of the standards and other important cross sections for ENDF/B-VI using these objective evaluation techniques.

The data base which was available for the ENDF/B-VI evaluation has been repeatedly discussed (for more recent examples see Refs. 7-11). Therefore, in the following we will mainly consider data which have become available since the ENDF/B-VI evaluation. Comparison with the evaluations will indicate possible problems.

\section{The ENDF/B-VI Evaluation}

The global evaluation of the standards and other important cross sections for ENDF/B-VI has been described previously. ${ }^{12-14}$ Therefore, only a brief account will be given here. A schematic of the global approach is shown in Fig. 2.

The evaluation process consisted of three major parts:

1. A simultaneous evaluation of $\mathbf{7 7 3}$ cross section and thermal parameters using the generalized least-squares fitting code GMA (for Gauss, Markov, Aitken).

2. R-matrix fits of the ${ }^{7} \mathrm{Li}$ and "B systems using the R-matrix code EDA (for Energy Dependent Analysis).

3. A procedure for combining the results from the parallel steps 1 and 2 .

The evaluation involved the ${ }^{6} \mathrm{Li}(\mathrm{n}, \mathrm{t}),{ }^{10} \mathrm{~B}\left(\mathrm{n}, \alpha_{0}\right),{ }^{10} \mathrm{~B}\left(\mathrm{n}, \alpha_{1}\right),{ }^{197} \mathrm{Au}(\mathrm{n}, \gamma),{ }^{235} \mathrm{U}(\mathrm{n}, \mathrm{f})$ standards as parameters. Other reference data like the ${ }^{3} \mathrm{He}(\mathrm{n}, \mathrm{p}), \mathrm{C}(\mathrm{n}, \mathrm{n})$ cross sections and the ${ }^{252} \mathrm{Cf}$-neutron spectrum were evaluated independently because they have very few correlations with the data involved in the global approach. The $\mathrm{H}(\mathrm{n}, \mathrm{p})$ cross sections had been originally included as parameters of the simultaneous 
evaluation ${ }^{5}$, however, adjustments of the $H(n, p)$ cross section were felt to represent the transfer of measurement errors and not cross section improvements. Therefore, a prior R-matrix analysis of the $\mathrm{H}(\mathrm{n}, \mathrm{p})$ cross section by Dodder and Hale ${ }^{1}$ was used, to convert all measurements relative to $H(n, p)$ into absolute or shape cross section data. Many data sets involve a normalization to therrnal cross sections. Instead of including the thermal cross section data base in the simultaneous evaluation, a recent evaluation of the thermal parameters (cross sections, g-factors, $\bar{\nu}$ ), often called thermal constants, of ${ }^{233} \mathrm{U},{ }^{235} \mathrm{U},{ }^{239} \mathrm{Pu}$ and ${ }^{211} \mathrm{Pu}$ by Axton ${ }^{15}$ with the associated covariance matrix was used as an input data set. The set of thermal parameters also contains $\bar{\nu}$ of ${ }^{252} \mathrm{Cf}$ which thereby became part of the global evaluation.

In addition to the standard cross sections, the scattering cross sections of ${ }^{6} \mathrm{Li}$ and ${ }^{10} \mathrm{~B}$ were used as parameters in order to utilize data of the total cross sections as an additional constraint. The ${ }^{238} \mathrm{U}(\mathrm{n}, \mathrm{f}),{ }^{238} \mathrm{U}(\mathrm{n}, \gamma)$ and ${ }^{239} \mathrm{Pu}(\mathrm{n}, \mathrm{f})$ cross sections were included in the simultaneous evaluation as parameters because many absolute cross section measurements are available for them due to their technological importance. These cross sections are also well interrelated with the standards due to ratio measurements. An energy grid was defined for the simultaneous evaluation which was the same for all cross sections. The parameters of the generalized least-squares fit were the cross sections at those grid points. Additional parameters were the thermal parameters mentioned above and the normalization constants of experimental shape data sets. The experimental data used in the simultaneous evaluation included absolute cross sections, cross section ratios and total cross sections. Shape data (the unnormalized energy dependence) of cross sections and cross section ratios were also used. It can be shown that the fission cross sections of ${ }^{235} \mathrm{U}(\mathrm{n}, \mathrm{f})$ and ${ }^{239} \mathrm{Pu}(\mathrm{n}, \mathrm{f})$ averaged over the neutron spectrum of the spontaneously fissioning ${ }^{252} \mathrm{Cf}$ are insensitive to uncertainties of that spectrum. These data provide valuable normalization information and have also been used.

The parameters of the $\mathrm{R}$-matrix fit are the resonance parameters of the ${ }^{6} \mathrm{Li}+\mathrm{n}$ and ${ }^{10} \mathrm{~B}+\mathrm{n}$ systems. The unitarity requirement imposes a constraint on the reaction channels. Theory describes not only the total and the integrated cross sections, but differential cross sections, polarization and inverse reaction data as well, thus experimental data for those have been used in the fits. The ${ }^{6} \mathrm{Li}$ and ${ }^{10} \mathrm{~B}$ data had to be partitioned between the simultaneous evaluation and the $R$-matrix evaluation. Because the $R$-matrix fits were made separately for the ${ }^{6} \mathrm{Li}+\mathrm{n}$ and the ${ }^{10} \mathrm{~B}+\mathrm{n}$ systems, all ratio data and data strongly correlated with other measurements remained in the GMA data base. Some data sets, which were originally in the GMA data base, were transferred to the EDA data base in order to speed up the convergence of the R-matrix fits.

The partitioning of the ${ }^{6} \mathrm{Li}$ and ${ }^{10} \mathrm{~B}$ data base left the simultaneous evaluation with poorer data, therefore resulting in larger uncertainties for the ${ }^{6} \mathrm{Li}$ and ${ }^{10} \mathrm{~B}$ cross 
sections from that analysis than that cbtained from the $R$-matrix results. As a consequence, the simultaneous evaluation results had lesser weight in the combination procedure for the ${ }^{6} \mathrm{Li}$ and ${ }^{10} \mathrm{~B}$ cross sections. This can be seen, for example, for ${ }^{6} \mathrm{Li}(\mathrm{n}, \mathrm{t})$ in Fig. 3 which shows the ratio of the GMA result to the EDA result as well as the ratio of the (final) combination result to the EDA result. Though the simultaneous evaluation resulted in $\sim 12 \%$ higher cross sections around $2 \mathrm{MeV}$ compared with the R-matrix solution, the combination procedure adjusted the $\mathrm{R}$-matrix result only by $\sim 3 \%$ in this range. On the other hand, for cross sections like ${ }^{235} \mathrm{U}(\mathrm{n}, \mathrm{f})$, the R-matrix results have very little impact on the combination result for energies above 1-2 $\mathrm{MeV}$ (see Fig. 4).

Data scarceness or inconsistencies at some energies introduce arbitrary fluctuations of the pointwise cross sections where they are known to be smooth based on the statistical-optical model. Therefore, as a final step of the evaluation process some smoothing was done for the ${ }^{197} \mathrm{Au}(\mathrm{n}, \gamma),{ }^{235} \mathrm{U}(\mathrm{n}, \mathrm{f}),{ }^{238} \mathrm{U}(\mathrm{n}, \mathrm{f}),{ }^{238} \mathrm{U}(\mathrm{n}, \gamma)$ and ${ }^{239} \mathrm{Pu}(\mathrm{n}, \mathrm{f})$ cross sections. The smoothing bas been done by comparing the pointwise data with theoretical calculations and attempting compensations of high and low values in local regions. Figure 5 shows as an example the difference of the pointwise combination result and the smoothed cross section of ${ }^{197} \mathrm{Au}(\mathrm{n}, \gamma)$.

III. ENDF/B-VI and New Experimental Data

III.1 The $\mathrm{H}(\mathrm{n}, \mathrm{p}),{ }^{3} \mathrm{He}(\mathrm{n}, \mathrm{p})$, and $\mathrm{C}(\mathrm{n}, \mathrm{n})$ Cross Sections

The H(n,p) cross sections of ENDF/B-III through ENDF/B-V were based on an analysis by Hopkins and Breit. ${ }^{17}$ A charge independent $R$-matrix analysis of $n-p$ and p-p experimental data below $30 \mathrm{MeV}$ by Dodder and Hale ${ }^{1}$ was adopted for ENDF/B-VI. Figure 6 shows the difference between the total cross sections of ENDF/B-VI and ENDF/B-V together with some of the more accurate measurements. The newest measurement by Priesmeyer et al. ${ }^{18}$ is $-0.24 \%$ lower than ENDF/B-VI. The largest difference between ENDF/B-VI and ENDF/B-V up to $20 \mathrm{MeV}$ is only $\sim 0.5 \%$. However, the center-of-mass system (CMS) scattering cross sections at $180^{\circ}$ differ by almost $2 \%$ near $11 \mathrm{MeV}$. This is significant because the $180^{\circ} \mathrm{CMS}$ neutron angle corresponds to a $0^{\circ}$ laboratory angle for the recoil protons, which is frequently used in proton recoil detectors for neutron fluence measurements. A recent measurement by Ryves and Kolkowski ${ }^{19}$ resulted in a $180^{\circ}$ cross section at $14.5 \mathrm{MeV}$ which is between the ENDF/B-V and ENDF/B-VI evaluations. A $\sigma\left(180^{\circ}\right) / \sigma\left(90^{\circ}\right)$ ratio of $1.053 \pm 0.015$ which also was measured in this experiment is consistent with ENDF/B-V but not with ENDF/B-VI for which the value is $1.093 \pm 0.010$.

The ${ }^{3} \mathrm{He}(\mathrm{n}, \mathrm{p})$ cross section is recognized as a standard up to $50 \mathrm{keV}$ neutron energy. The ENDF/B-VI evaluation led to a considerable improvement in data 


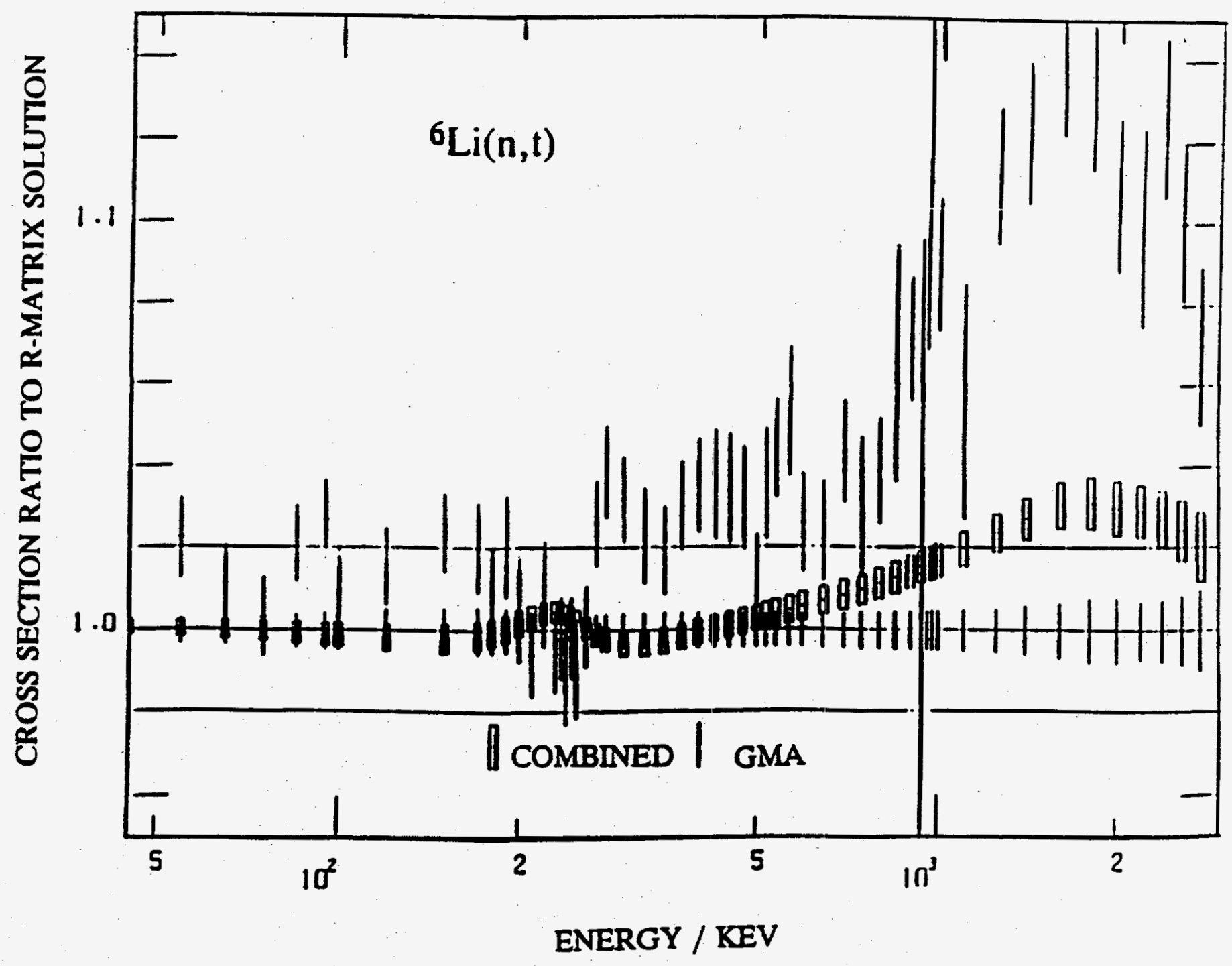

Fig. 3 The Combination Result and the GMA Input Relative to the R-Matrix Input of ${ }^{6} \mathrm{Li}(\mathrm{n}, \mathrm{t})$ 


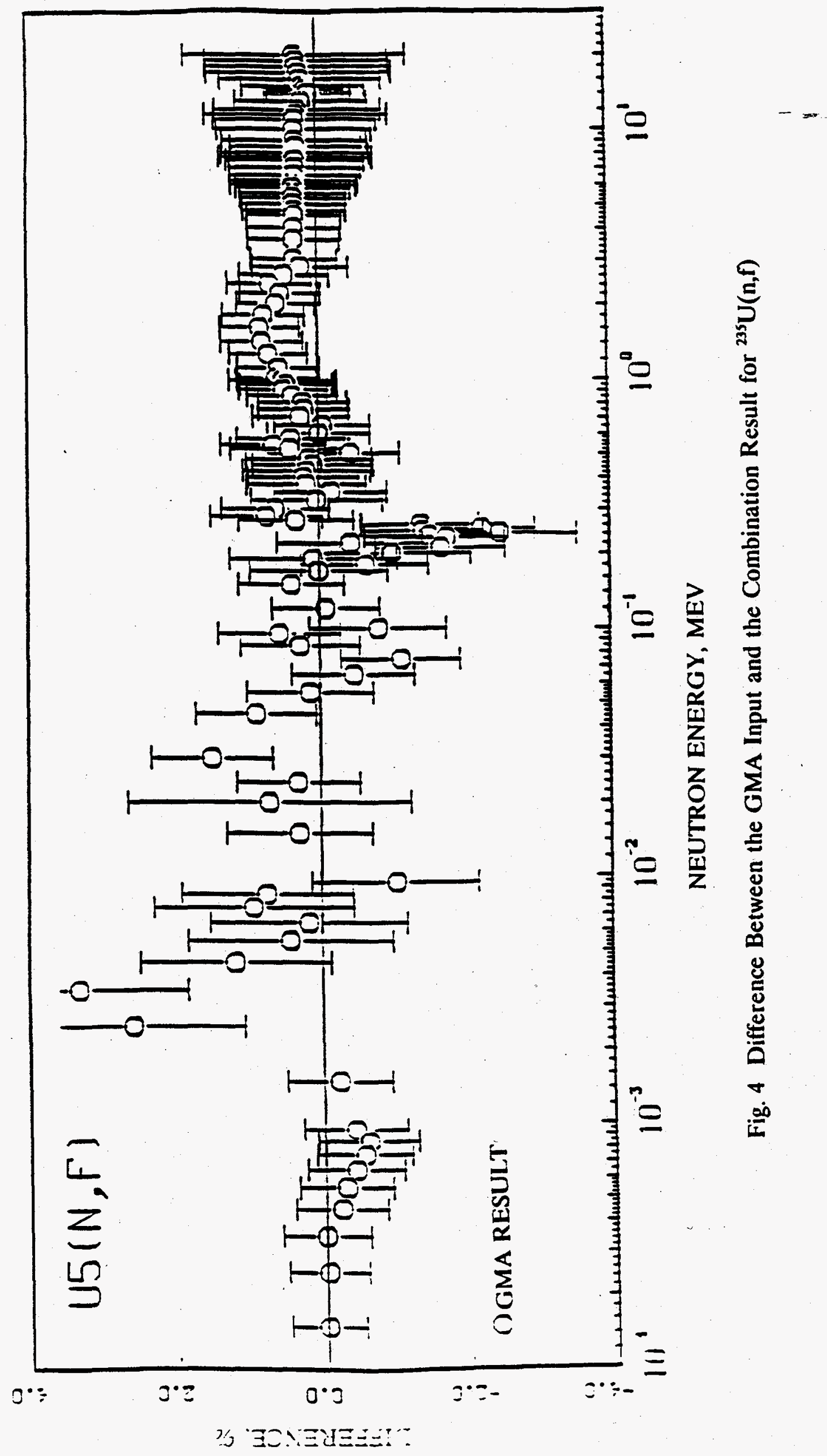




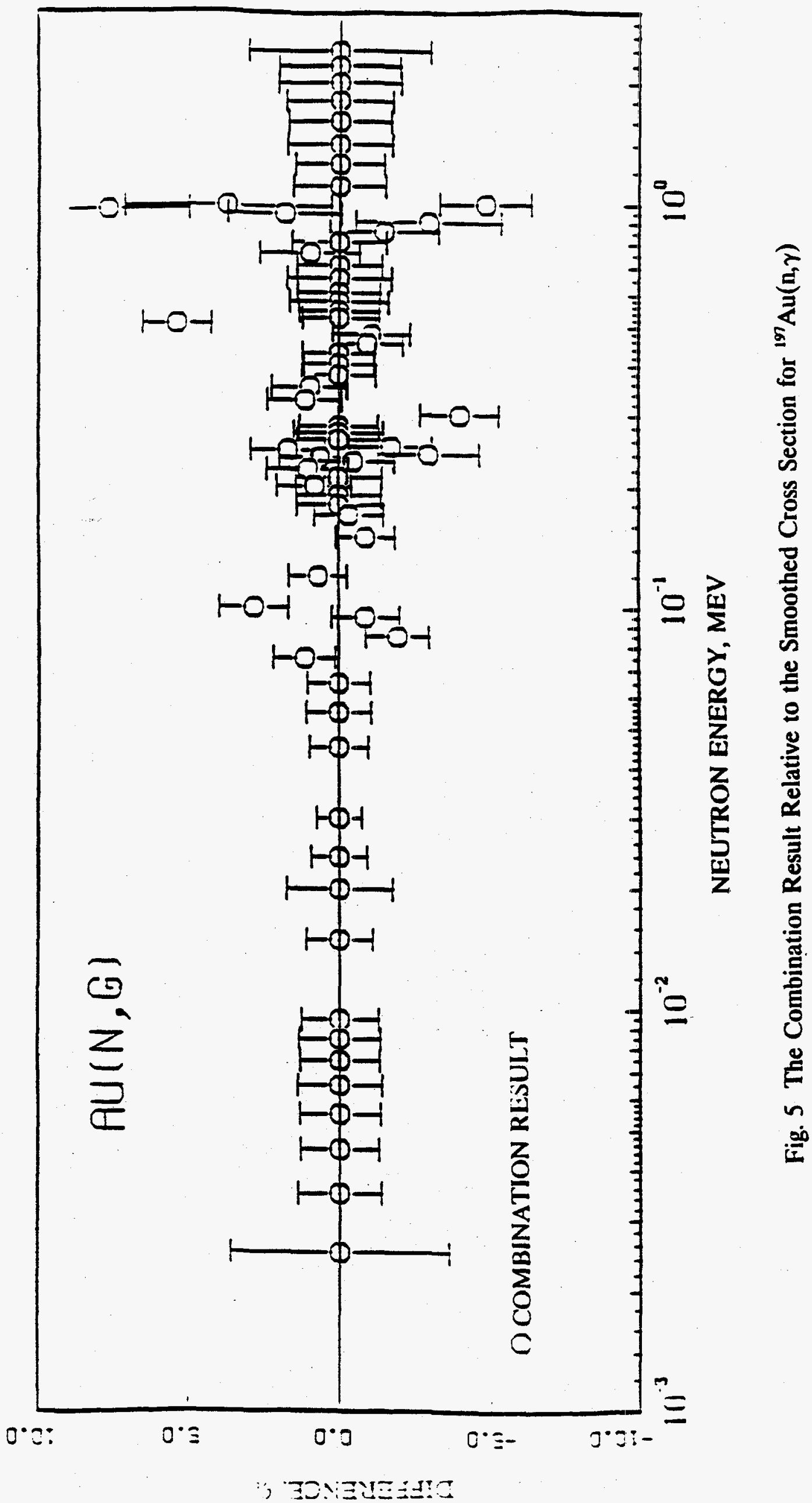




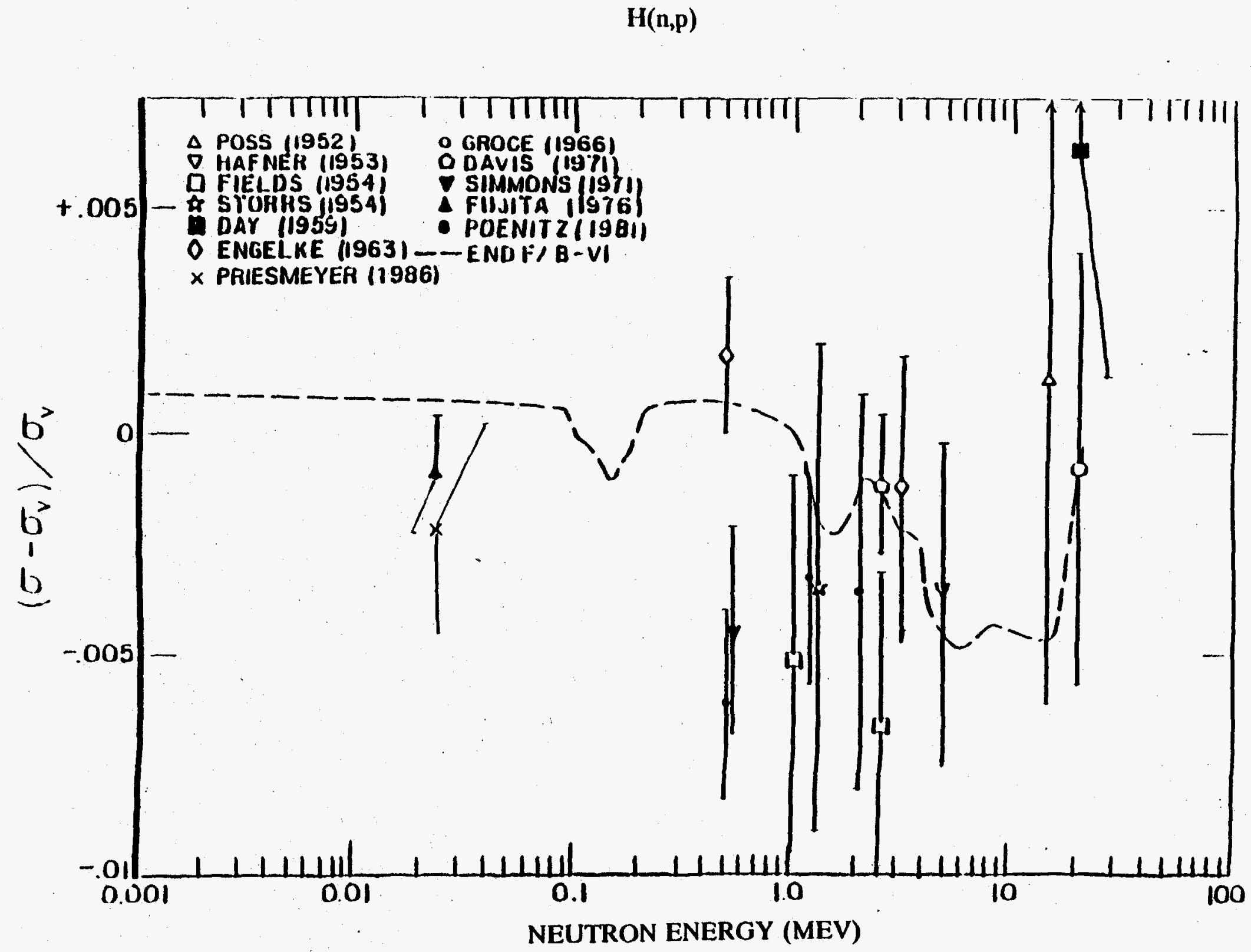

Fig. 6. Comparison of High Accuracy Measurements of the Hydrogen Total Neutron Cross Section and the ENDF/B-V and ENDF/B-VI Evaluations. The References for the

Experimental Data are Given in Ref. 10 
quality for this cross section since the last ENDF evaluation of this cross section was performed in 1968 for ENDF/B-III. That evaluation was carried over intact to versions IV and V of ENDF/B. The ENDF/B-VI evaluation was an R-matrix analysis done by $\mathrm{Hale}^{2}$ using all possible two body reactions in the ${ }^{4} \mathrm{He}$ system. Measurements have been made of this cross section by Borzakov ${ }^{20}$ from 0.26 to $142 \mathrm{keV}$ neutron energy relative to the ${ }^{6} \mathrm{Li}(n, t)$ standard cross section. These measurements are in excellent agreement with the ENDF/B-VI evaluation in the standards energy region.

The natural carbon scattering cross section is used as a scattering standard up to $2 \mathrm{MeV}$. The evaluation for ENDF/B-V was based on an R-matrix analysis of ${ }^{12} \mathrm{C}$ by $\mathrm{Fu}^{3}$. The evaluation for ENDF/B-VI was modified in order to include two resonances of ${ }^{13} \mathrm{C}$ (1.1\% abundance) so that the evaluation would be appropriate for natural carbon. New measurements by Schmiedmayer and Moxon $^{21}$ in the energy region from $50 \mathrm{eV}$ to $100 \mathrm{keV}$ are in excellent agreement with the ENDF evaluation. Also a filtered neutron beam measurement at $2 \mathrm{keV}$ by Kirilyuk ${ }^{22}$ is in very good agreement with the evaluation.

\section{III.2 The ${ }^{6} \mathrm{Li}(\mathrm{n}, \mathrm{t})$ and ${ }^{10} \mathrm{~B}(\mathrm{n}, \alpha)$ Cross Sections}

The cross section data base for ${ }^{6} \mathrm{Li}$ and ${ }^{10} \mathrm{~B}$ has been reviewed recently in Refs. 9 and 10. New data for the ${ }^{6} \mathrm{Li}(\mathrm{n}, \mathrm{t})$ cross section have not become available since the evaluation for ENDF/B-VI. It had been the conclusion in Ref. 9 that the ${ }^{6} \mathrm{Li}(\mathrm{n}, \mathrm{t})$ cross section is reasonably well known but that substantial discrepancies exist for the ${ }^{10} \mathrm{~B}$ cross sections. An NEANSC endorsed international inter-laboratory collaboration group was formed in order to provide a mechanism for improving the ${ }^{10} \mathrm{~B}(\mathrm{n}, \alpha)$ cross sections.

New measurements of the shape of the ${ }^{10} \mathrm{~B}\left(\mathrm{n}, \alpha_{1}\right)$ cross section have been made by Schrack et l. $^{23}$ The data, normalized to ENDF/B-VI between 200 and $360 \mathrm{keV}$, are shown in Fig. 7 compared with the ENDF/B-VI global evaluation result. With the exception of the resonance at $500 \mathrm{keV}$, the agreement is very good up to $1 \mathrm{MeV}$ where the global evaluation for the ${ }^{10} \mathrm{~B}$ cross sections ended. This agreement is important because the ENDF/B-VI values for this cross section increased relative to ENDF/B-V by up to $20 \%$ between $400 \mathrm{keV}$ and $1 \mathrm{MeV}$. Large differences occur between the new measurement and ENDF/B-VI above $1.5 \mathrm{MeV}(+15 \%$ around $2 \mathrm{MeV}$ and $-30 \%$ around $3 \mathrm{MeV}$ ).

A new measurement of the cross section ratio $\sigma\left(n, \alpha_{0}\right) / \sigma\left(n, \alpha_{1}\right)$ by Weston and Todd $^{24}$ became available after the ENDF/B-VI evaluation had been concluded. The data are shown and compared with ENDF/B-VI in Fig. 8. The discrepancy is obvious. However, including the new data in the evaluation would probably have little effect on the outcome below $100 \mathrm{keV}$ (because of the reasonable agreement) 


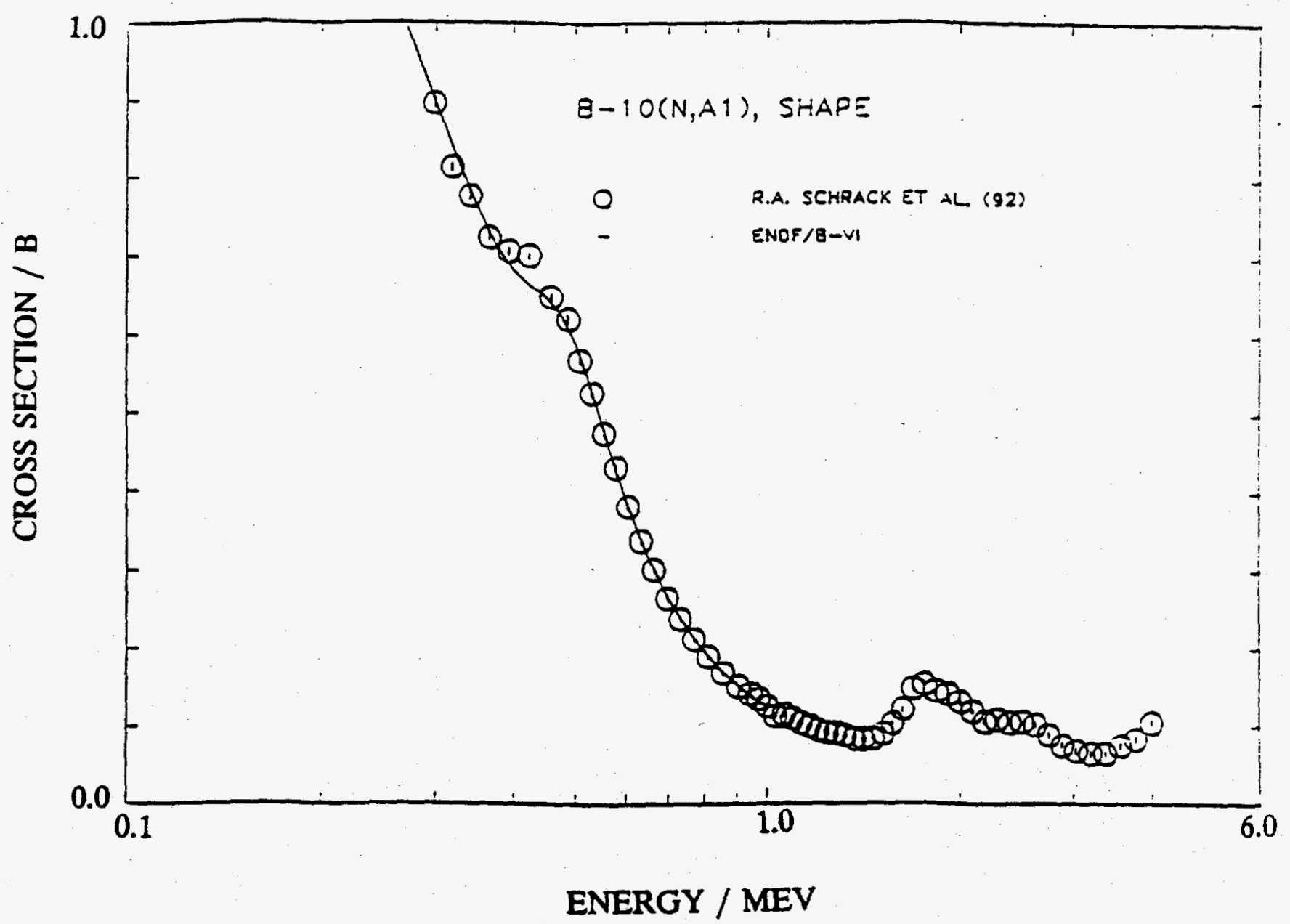

Fig. 7 Comparison of the Result for ${ }^{10} \mathrm{~B}(\mathrm{n}, \alpha \gamma)$ from the Global Evaluation with New Measurements by Schrack et $a i^{23}$ 


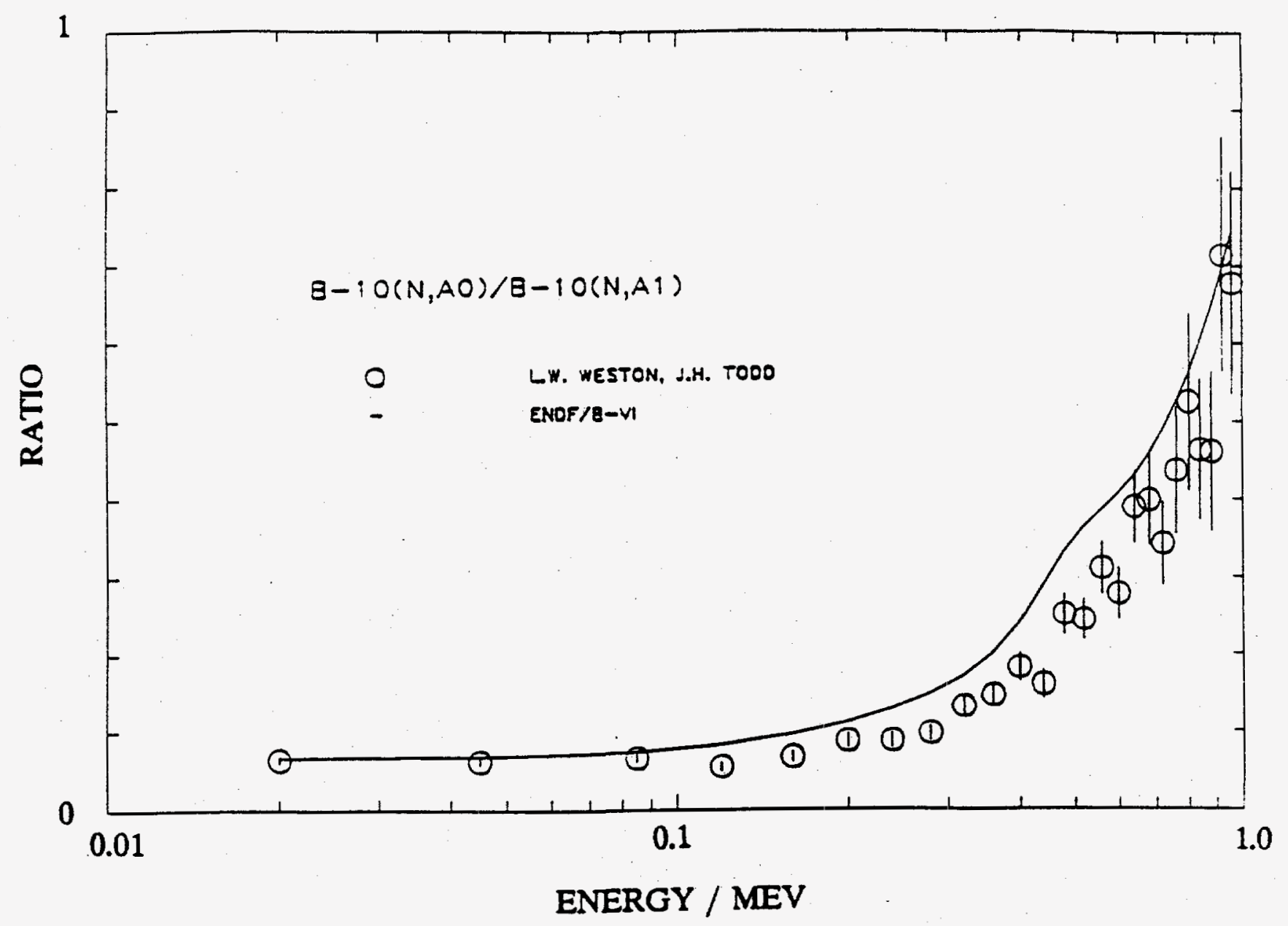

Fig. 8 Comparison of the Result for ${ }^{10} \mathrm{~B}\left(\mathrm{n}, \alpha_{0}\right)$ vs ${ }^{10} \mathrm{~B}\left(\mathrm{n}, \alpha_{1}\right)$ from the Global Evaluation with New Measurements by Weston \& Todd $^{24}$ 
and above $400 \mathrm{keV}$ (because of the large uncertainties of the new data). The ENDF/B-VI evaluation of ${ }^{10} \mathrm{~B}\left(\mathrm{n}, \alpha_{0}\right)$ was strongly influenced by the inverse reaction cross section measurement of Olson and Kavanagh. ${ }^{25}$

The ratio of the ENDF/B-VI cross sections to those of ENDF/B-V for ${ }^{10} \mathrm{~B}(\mathrm{n}, \alpha)$, the sum of the ${ }^{10} \mathrm{~B}\left(\mathrm{n}, \alpha_{0}\right)$ and ${ }^{10} \mathrm{~B}\left(\mathrm{n}, \alpha_{1}\right)$ cross sections, is shown in Fig. 9. Also shown are the adjustments made to group cross sections for ${ }^{10} \mathrm{~B}(\mathrm{n}, \alpha)$ which are required in order to bring a large number of calculated fast reactor integral quantities into better agreement with experiment. ${ }^{26}$ Control rod worth, small ${ }^{10} \mathrm{~B}$ sample worth and Helium production in Boron are the quantities most affected by the ${ }^{10} \mathrm{~B}(\mathrm{n}, \alpha)$ cross section adjustment. It can be seen from Fig. 9 that the change from ENDF/B-V to ENDF/B-VI will be beneficial for the calculation of these quantities and reduce the $C / E$ (for calculated vs. experiment) discrepancies.

\section{III.3 The ${ }^{197} \mathrm{Au}(\mathrm{n}, \gamma)$ and ${ }^{238} \mathrm{U}(\mathrm{n}, \gamma)$ Cross Sections}

New measurements of the ${ }^{197} \mathrm{Au}(\mathrm{n}, \gamma)$ cross section using calibrated photoneutron sources $^{27}$ are shown in Fig. 10. These data are somewhat lower at $23 \mathrm{keV}$ and substantially higher $(-20 \%)$ at $967 \mathrm{keV}$ compared with ENDF/B-VI. Around $1 \mathrm{MeV}$ the ENDF/B-VI evaluation agrees well with absolute measurements and ${ }^{197} \mathrm{Au}(\mathrm{n}, \gamma) /{ }^{235} \mathrm{U}(\mathrm{n}, \mathrm{f})$ data. A previous photoneuton source measurement ${ }^{23}$, however, also resulted in a high value at $967 \mathrm{keV}$ similar to that of the newest measurement. Revised and new data by Davletshin et al ${ }^{29}$ were measured relative to the $H(n, p)$ cross section and are also shown in Fig. 10., together with new data by Kazakov et $a{ }^{30}$ and some additional data by Davletshin et al ${ }^{29}$ referenced to ${ }^{235} \mathrm{U}(\mathrm{n}, \mathrm{f})$ of ENDF/B-VI. The agreement with ENDF/B-VI overall is good, but there might be a problem around the inelastic levels at $270 \mathrm{keV}$. Values by Demekhin et $\mathrm{al}^{31}$ and by Voiniers ${ }^{55}$ above $2 \mathrm{MeV}$ are higher than the evaluation.

${ }^{238} \mathrm{U}(\mathrm{n}, \gamma)$ values were obtained with the same calibrated photoneutron sources ${ }^{32}$ used for the $\mathrm{Au}(\mathrm{n}, \gamma)$ measurements mentioned above. They are shown in Fig. 11 together with the result from the global evaluation. The agreement is quite good at $23 \mathrm{keV}$ but the $967 \mathrm{keV}$ value is again higher than ENDF/B-VI. Other recent measurements by Kobayashi et al ${ }^{33}$ were made with $\mathrm{Fe}$ and $\mathrm{Sc}$ filtered beams, and normalized at $24 \mathrm{keV}$ to the ENDF/B-VI value. New measurements by Adamchuk et $a L^{34}$ using a multiplicity detector as well as data by Buleeva $e t a{ }^{35}$ relative to $\mathrm{H}(\mathrm{n}, \mathrm{p})$ are also shown in Fig. 11. There is good agreement between these measurements and the evaluation.

An evaluation of ${ }^{238} U$ in the unresolved resonance range was made by Froehner ${ }^{36}$ using an optical/statistical model code. The data utilized in the fit were total, scattering (elastic and inelastic), capture cross sections, and strength functions from the resolved resonance range. The result from this evaluation (JEF-2) is shown in 


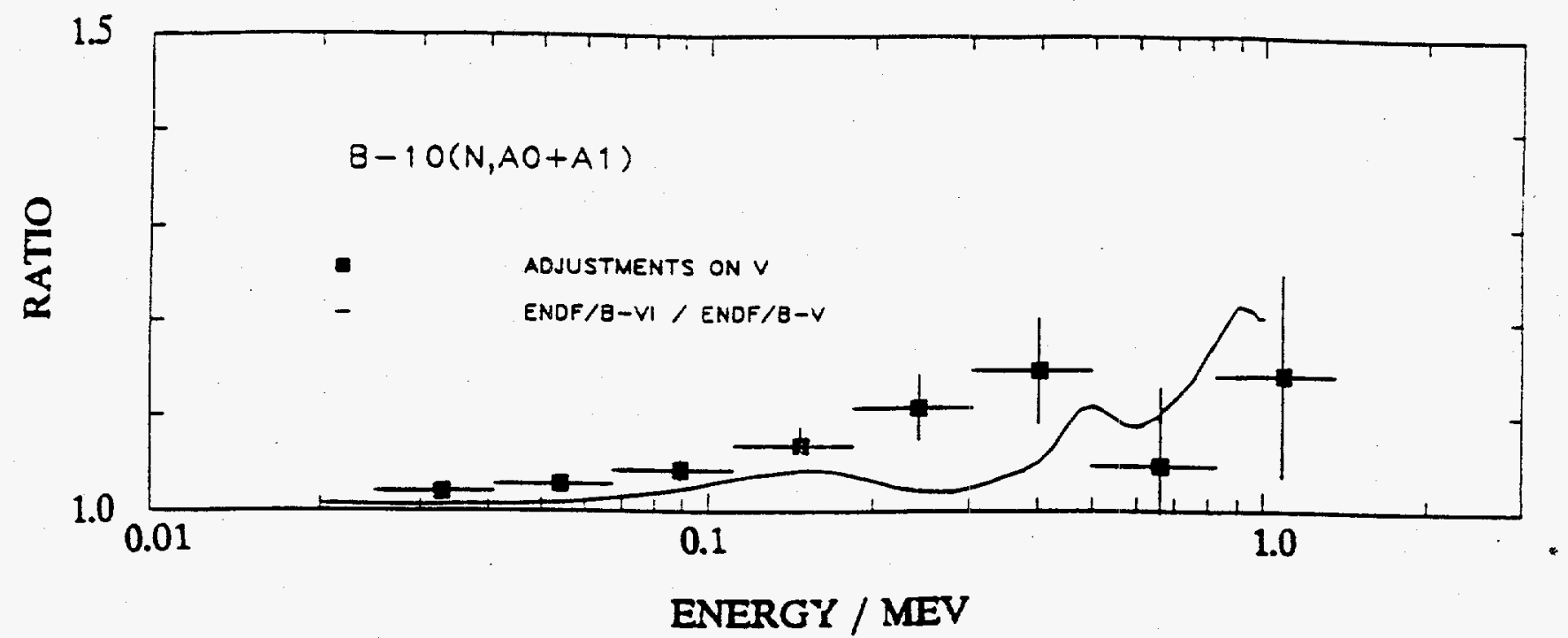

Fig. 9 Comparison of Cross Section Adjustments of ENDF/B.V ${ }^{10} B(n, \alpha)$ Required by Integral Data and the Ratio of ENDF/B-VI to V 


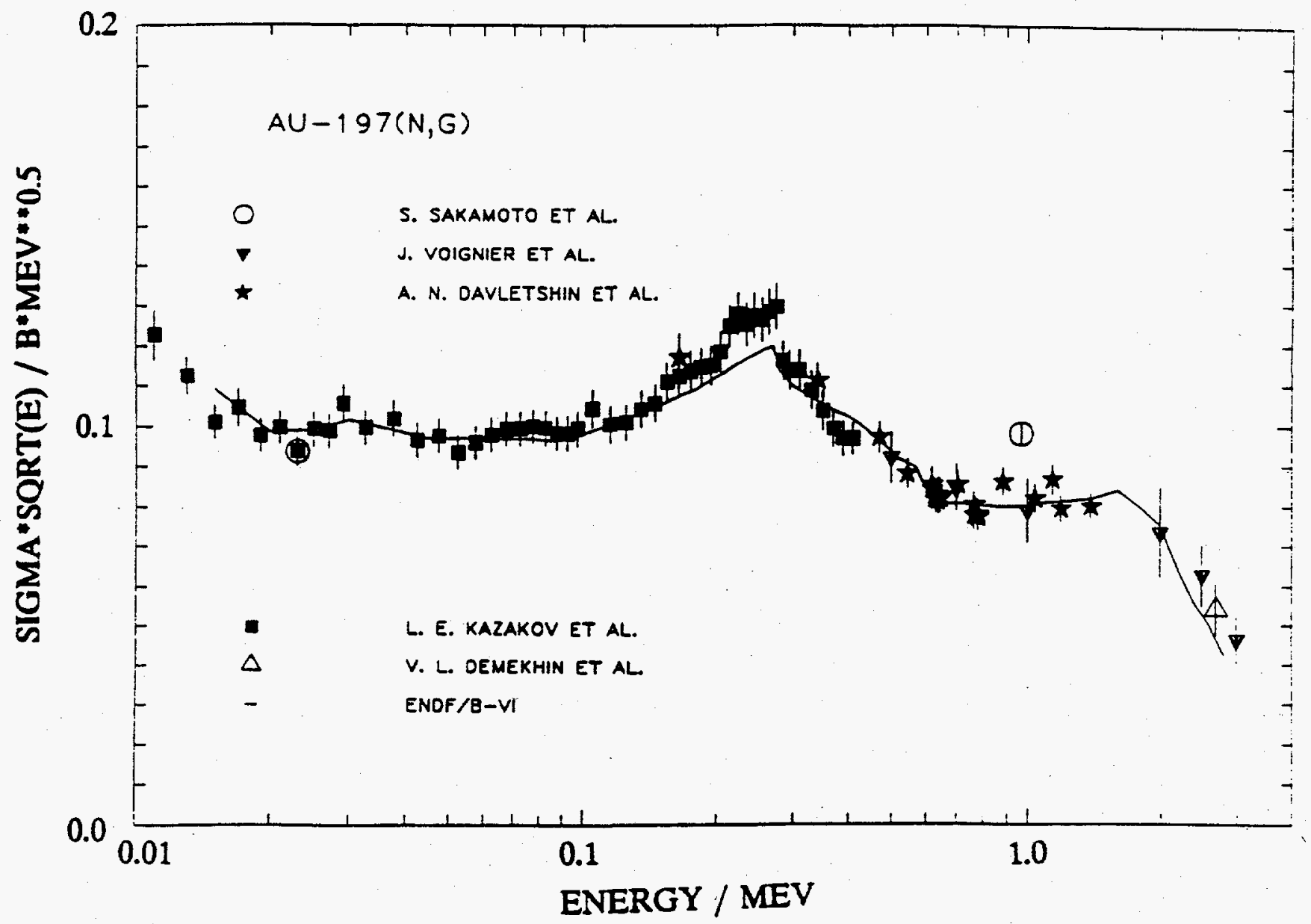

Fig. 10 Comparison of the Global Evaluation Result (ENDF B-VI) for ${ }^{197} \mathrm{Au}(\mathrm{n}, y)$ with New Experimental Data 


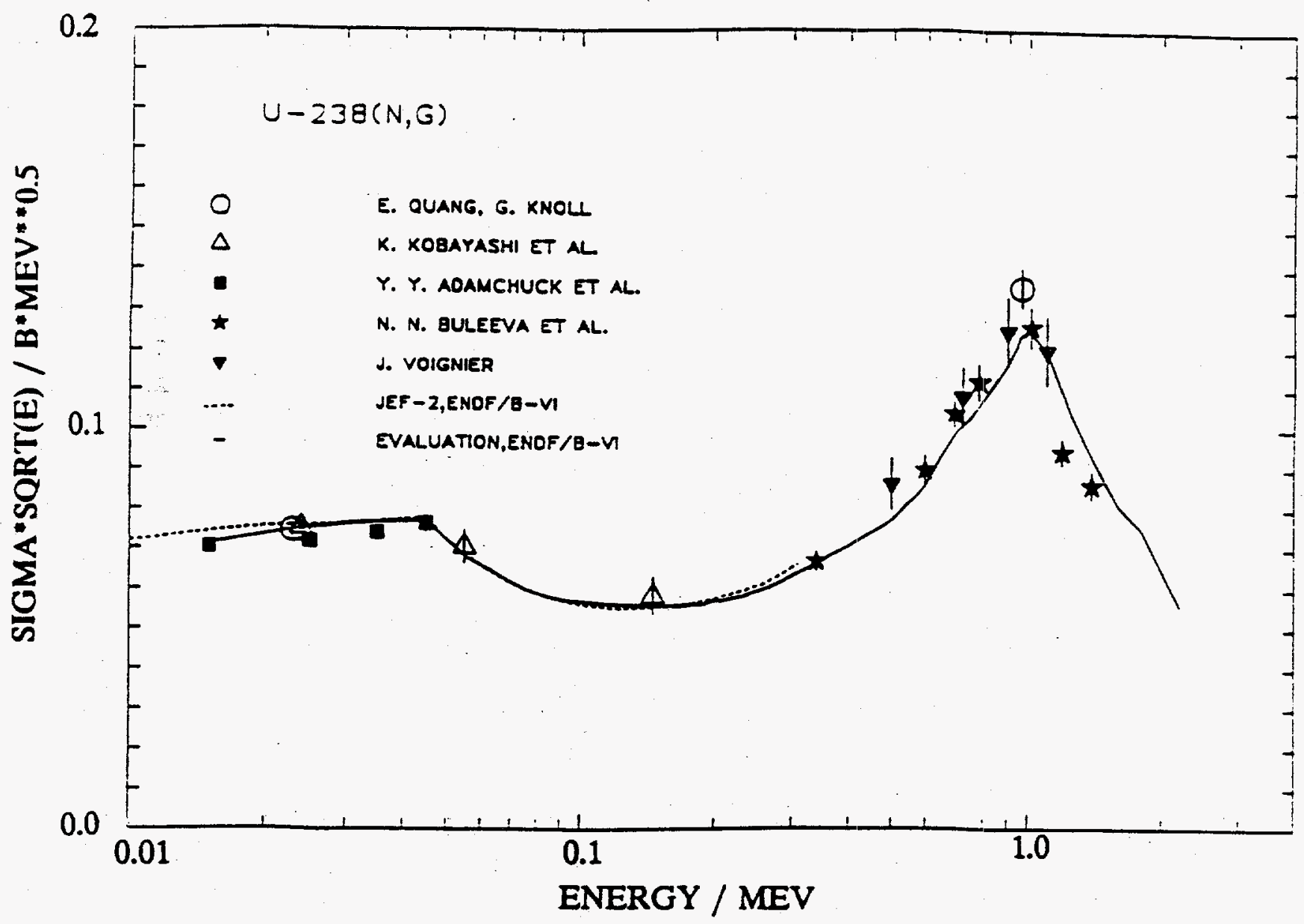

Fig. 11 Comparison of the Global Evaluation Result for ${ }^{238} \mathrm{U}(\mathrm{n}, \gamma)$ with New 2. Measurements. ENDF/B-VI is Identical to JEF-2 Below $148 \mathrm{keV}$

3

अ 
Fig. 11. There is an astonishingly good agreement between the results from the two different approaches. The unresolved resonance parameters from the work by Froehner have been used for ENDF/B-VI, thus the ENDF/B-VI and JEF-2 files are identical up to $148 \mathrm{keV}$.

III.4 The ${ }^{235} U(n, f)$ and ${ }^{238} U(n, f)$ Cross Sections

A substantial number of new measurements have been made of the ${ }^{235} U(n, f)$ cross section since the evaluation for ENDF/B-VI was completed. Figures 12-14 show two data sets which recently have been finalized or revised, ${ }^{37,38}$ but had been available and used for the simultaneous evaluation with GMA, as well as several other new data sets. The final data by Carison $e t$ al. ${ }^{37}$ differ from the GMA input only by minor amounts. However, the data from the Technical University of Dresden (TUD)/Radium Institute of Leningrad (RIL) collaboration ${ }^{38}$ have been changed by amounts which very often exceed the original quoted uncertainties. ${ }^{39}$ The revisions were due to changes in the corrections for fission fragment absorption (FFA) and new measurements of the areal densities of the fissile material. The initial insufficient corrections for FFA were recognized prior to the GMA evaluation ${ }^{40}$ and additional corrections were made; however, not to the extent made for the final values in Ref. 38. The revised values at $2.56,4.45$ and $14.7 \mathrm{MeV}$ agree very well with the ENDF/B-VI evaluation. New shape measurements by Carlson et al. ${ }^{41}$ and by Lisowski et al. $^{42}$ which are shown in Figs. 13 and 14, normalized around $14 \mathrm{MeV}$ to ENDF/B-VI, support higher cross sections than ENDF/B-VI above $15 \mathrm{MeV}$ but agree very well with ENDF/B-VI at all other energies, specifically around $8 \mathrm{MeV}$. Data by Buleeva et al. ${ }^{35}$ were measured relative to the $H(n, p)$ cross section and agree reasonably with ENDF/B-VI (see Fig. 12).

Two more ${ }^{235} U(n, f)$ data sets which were not available for the GMA evaluation are shown in Fig. 15. The data by Johnson et al..$^{43}$ are correlated with the data by Carlson et al. ${ }^{37}$ because the same fission chamber was used. The agreement with ENDF/B-VI is very good. The measurements by Iwasaki $e t$ al. ${ }^{\text {th }}$ were made with a recoil proton telescope for the determination of the neutron fluence. The cross sections have total uncertainties of about $2.5 \%$. The originally quoted values were in very good agreement with the ENDF/B-VI ${ }^{25 S} \mathrm{U}(\mathrm{n}, \mathrm{f})$ evaluation. However when the data are converted using the ENDF/B-VI hydrogen cross sections instead of ENDF/B-V, an increase of $1.7 \%$ occurs. An experimental check was made of the telescope by determining fluence with the telescope using ENDF/B-V hydrogen cross sections and comparing this with that obtained using the time-correlated associatedparticle technique. This agreement was within $1 \%$ with uncertainties of $2 \%$. These measurements suggest that the ENDF/B-VI hydrogen cross sections may be too high at $14 \mathrm{MeV}$ for a CMS scattering angle of 180 degrees; however the uncertainties make this conclusion quite tentative. 


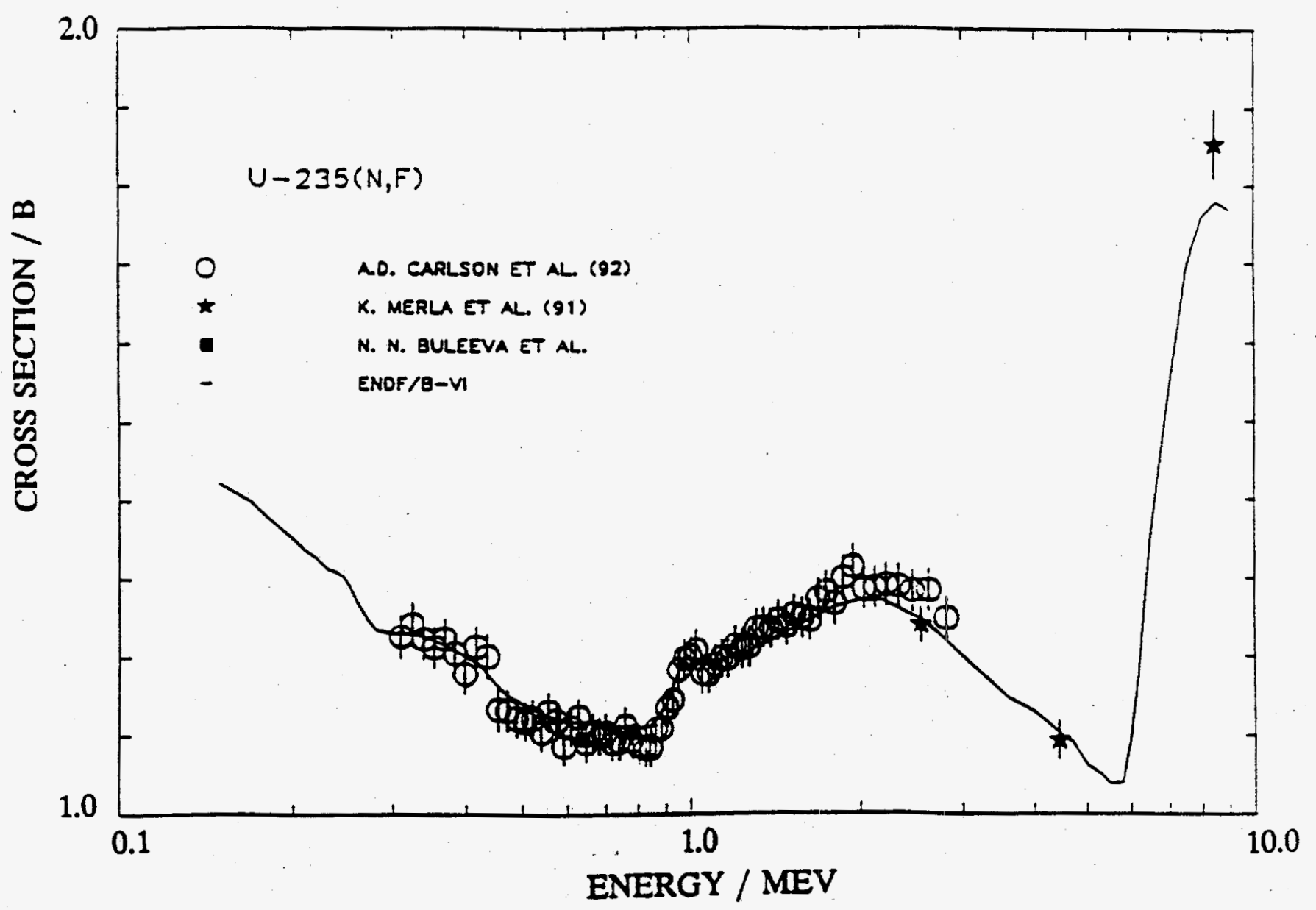

Fig. 12 Comparison of the Result of the Global Evaluation (ENDF/B-VI) for ${ }^{235} \mathrm{U}(\mathrm{n}, \mathrm{f})$ with New or Revised Experimental Data 


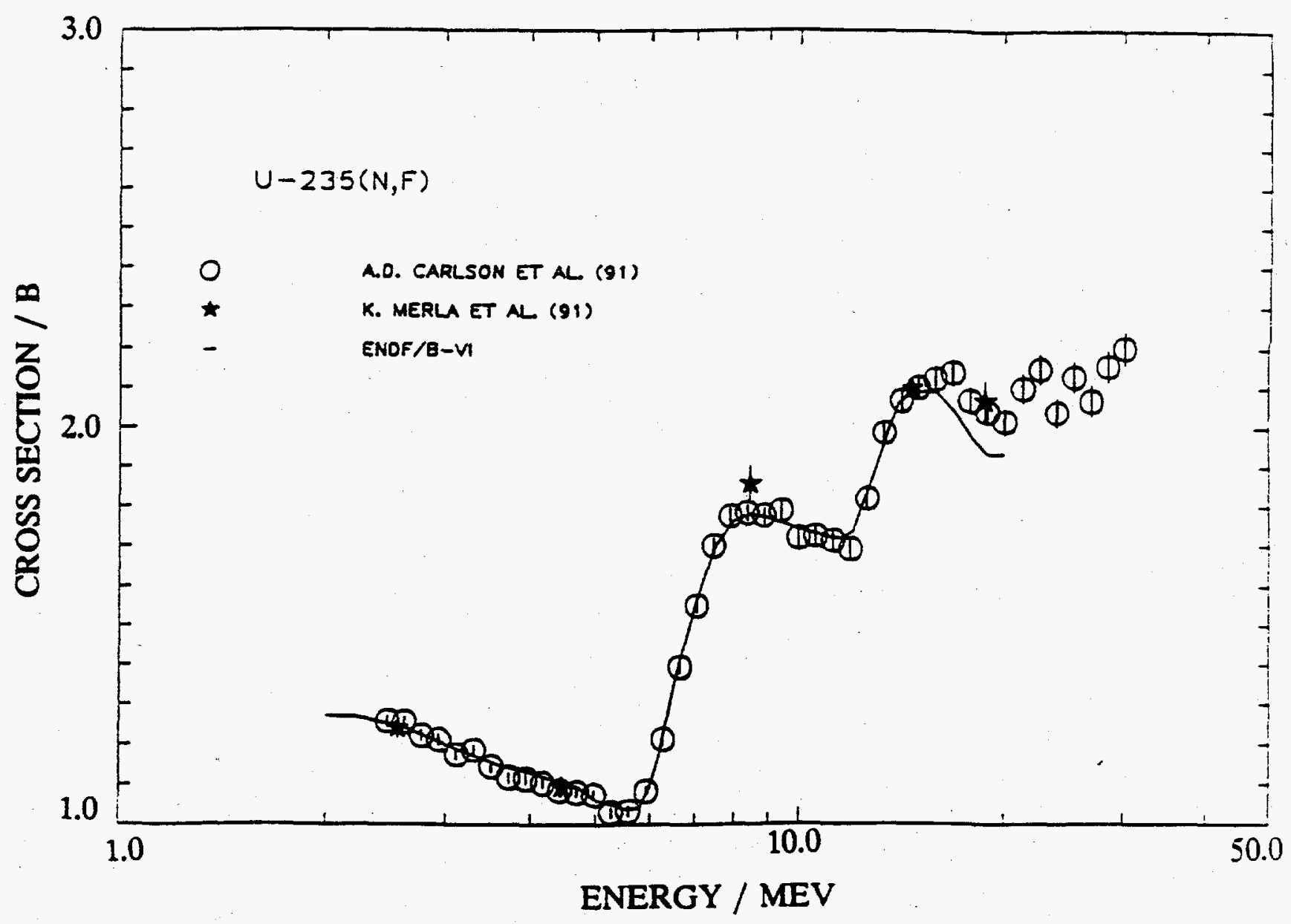

Fig. 13 Comparison of the Result of the Global Evaluation (ENDF/B-VI) for ${ }^{235} \mathrm{U}(\mathrm{n}, \mathrm{f})$ with New or Revised Experimental Data 


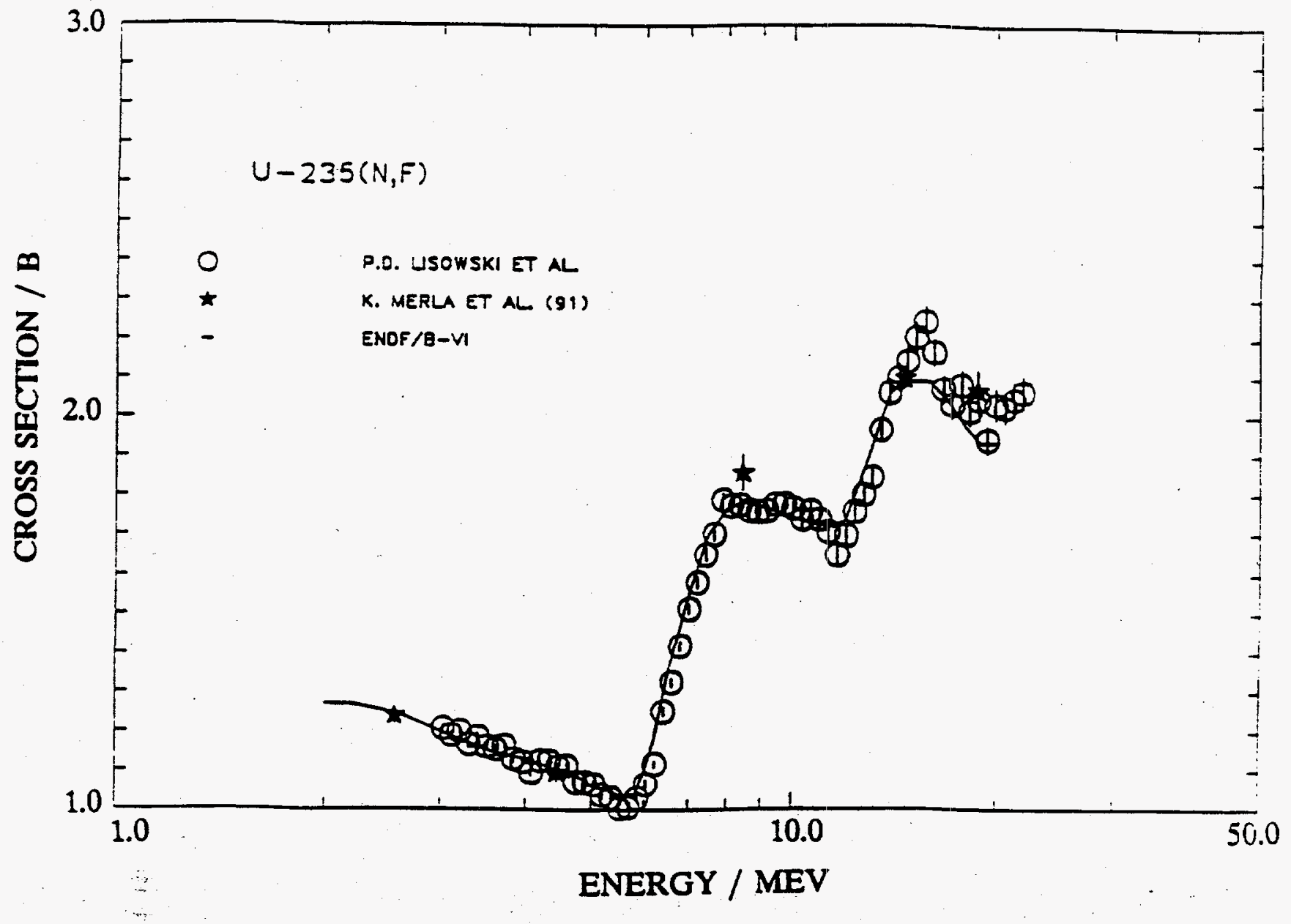

Fig. 14 Comparison of the Result of the Global Evaluation (ENDF/B-VI) for ${ }^{235} U(n, f)$ with New or Revised Experimental Data 


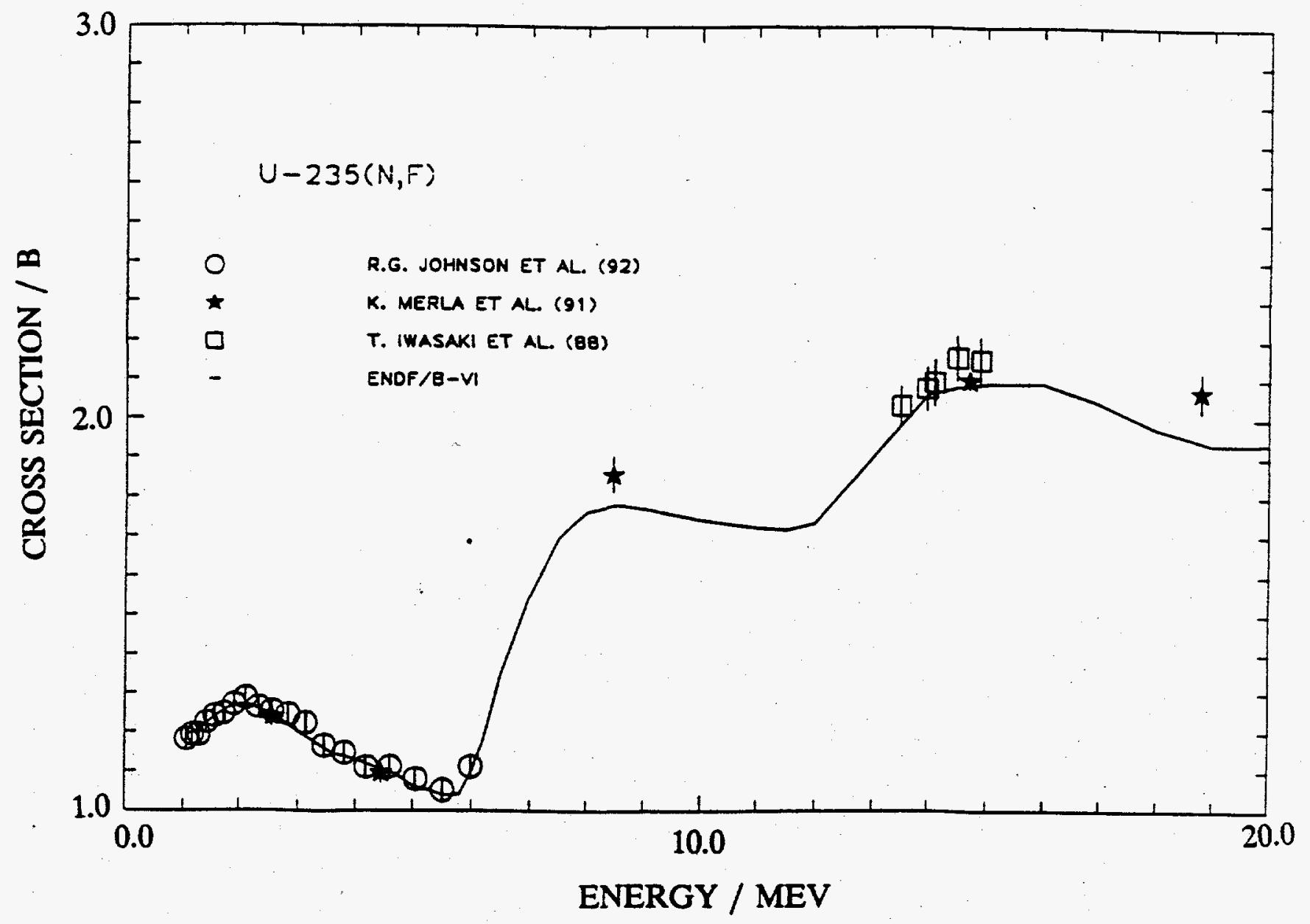

Fig. 15 Comparison of the Result of the Global Evaluation (ENDF/B-VI) for ${ }^{235} U(n, f)$ with New or Revised Experimental Data 
Figure 16 shows the revised value for the ${ }^{238} \mathrm{U}(\mathrm{n}, \mathrm{f})$ cross section at $14.7 \mathrm{MeV}$ as well as some new data from the TUD/RIL collaboration ${ }^{38}$ The value at $14.7 \mathrm{MeV}$ has been changed by $+5.2 \%$ compared with the value available for the GMA evaluation, which is 3.7 times the uncertainty quoted in Ref. 39. Another new value at $14.5 \mathrm{MeV}$ obtained by Winkler et al. ${ }^{45}$ is also shown in Fig. 16. In the latter experiment the neutron fluence was obtained with the associated particle technique as well as relative to the ${ }^{n} \mathrm{Al}(\mathrm{n}, \alpha)$ and ${ }^{56} \mathrm{Fe}(\mathrm{n}, \mathrm{p})$ cross sections of the International Reactor Dosimetry File $-90^{46}$ with good agreement among the three values. The ${ }^{238} \mathrm{U}$ mass was based on alpha counting at four different laboratories. The new and revised data shown in Fig. 16 apparently suggest a ${ }^{238} \mathrm{U}(\mathrm{n}, \mathrm{f})$ cross section higher than ENDF/B-VI ranging from $-2.5 \%$ around $5 \mathrm{MeV},-4.2 \%$ around $14 \mathrm{MeV}$ to $\sim 5.6 \%$ at 18-19 MeV. Absolute cross sections with low uncertainties which were available for the GMA input data are compared with the result of the global evaluation in Fig. 17. The data by Wu Jingxia et al..$^{47}$ would support a cross section $\sim 2.5 \%$ higher than ENDF/B-VI around 4.0 -5.5 MeV, though the values agree within the uncertainties. However, what mostly determined the outcome for the ${ }^{238} U(n, f)$ evaluation was the large amount of data available from cross section ratio measurements of ${ }^{238} U(n, f)$ to ${ }^{235} U(n, f)$. A few of such ratio values are shown in Fig. 18 as a difference to the result of the globall evaluation. The value by Meadows ${ }^{48}$ would support a $14.7 \mathrm{MeV}{ }^{238} \mathrm{U}(\mathrm{n}, \mathrm{f})$ cross section $\sim 4 \%$ higher than ENDF/B-VI. This value had been of some concern during the evaluation for ENDF/B-VI. ${ }^{49}$ However, although it has a low uncertainty, it was "swamped" by $\sim 15$ other data sets which contradict it and agree well with ENDF/B-VI. Of specific interest are the data by Behrens and Carlson ${ }^{50}$ and by Difilippo et al. ${ }^{51}$. These data extend over the whole energy range from threshold to $20 \mathrm{MeV}$, therefore they transfer information available at lower energies from many other experiments to the range shown in Fig. 18. Ratios of the revised to new data from the TUD/RIL collaboration are nearly identical with the ENDF/B-VI ratio at $8.2 \mathrm{MeV}$ and at $18.8 \mathrm{MeV}$, but are identical with the ratio measured by Meadows at $14.7 \mathrm{MeV}$. Nothing can be seen in the available data sets which would explain a "local bump" around $14-15 \mathrm{MeV}$.

A new measurement of the ${ }^{238} \mathrm{U}(\mathrm{n}, \mathrm{f}) /{ }^{235} \mathrm{U}(\mathrm{n}, \mathrm{f})$ cross section ratio has been made by Lisowski et al. ${ }^{52}$ These data are preliminary and extend to several hundred $\mathrm{MeV}$, the portion to $20 \mathrm{MeV}$ is compared with ENDF/B-VI in Fig. 19. The agreement is good, thus again questioning the new results shown in Fig. 16. Another measurement of the ratio ${ }^{53}$ is in agreement with or lower than the data by Difilippo et al ${ }^{\text {st }}$. Baba et al ${ }^{54}$ made measurements of the ratio and mention that their data are $\sim 3 \%$ higher than Jendl-2 but that the accuracy is not as good as that of other recent experiments. 


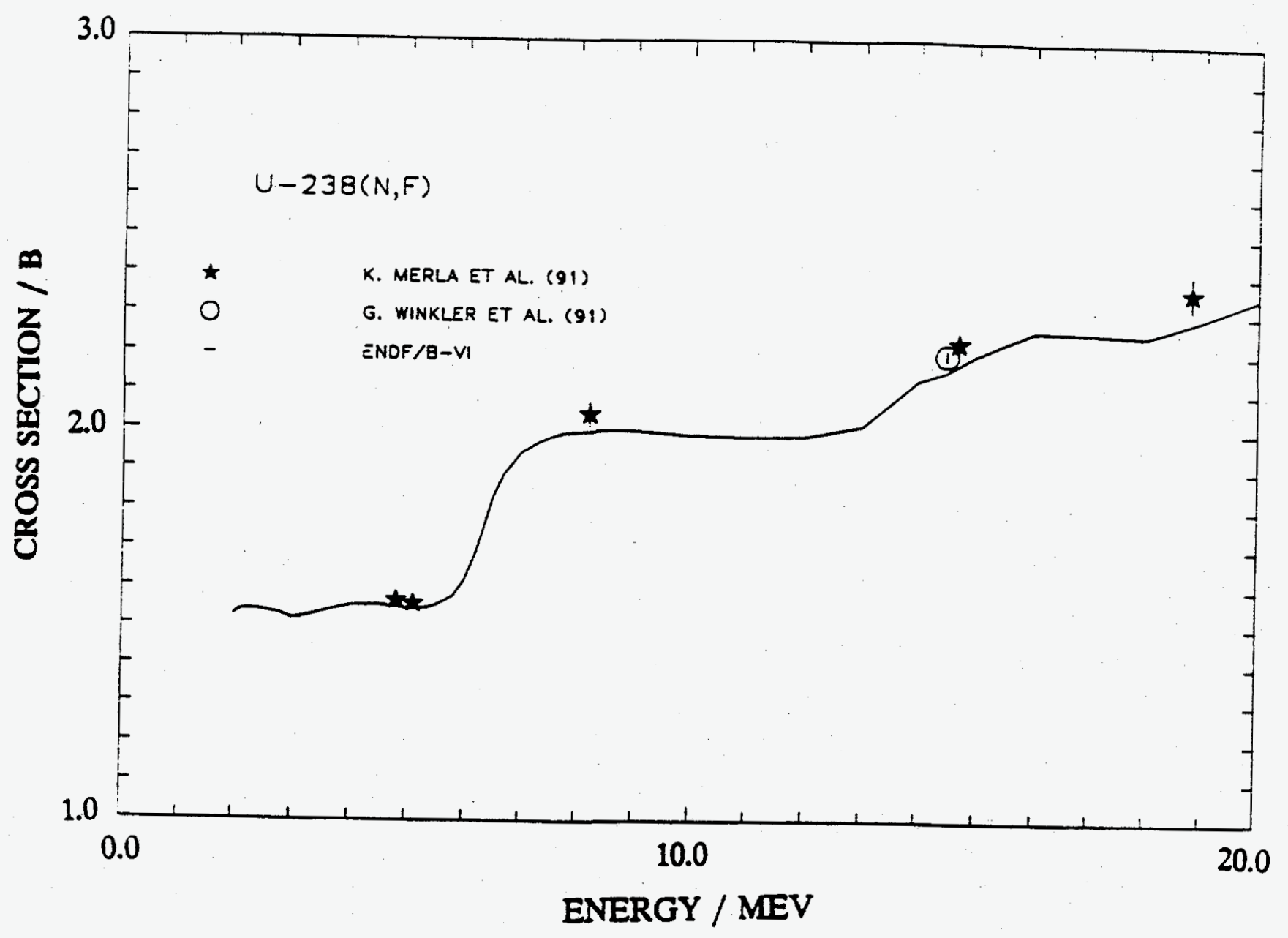

Fig. 16 Comparison of the Global Evaluation Result for ${ }^{238} \mathrm{U}(\mathrm{n}, \mathrm{f})$ (ENDF/B-VI) with New and Revised Experimental Data 


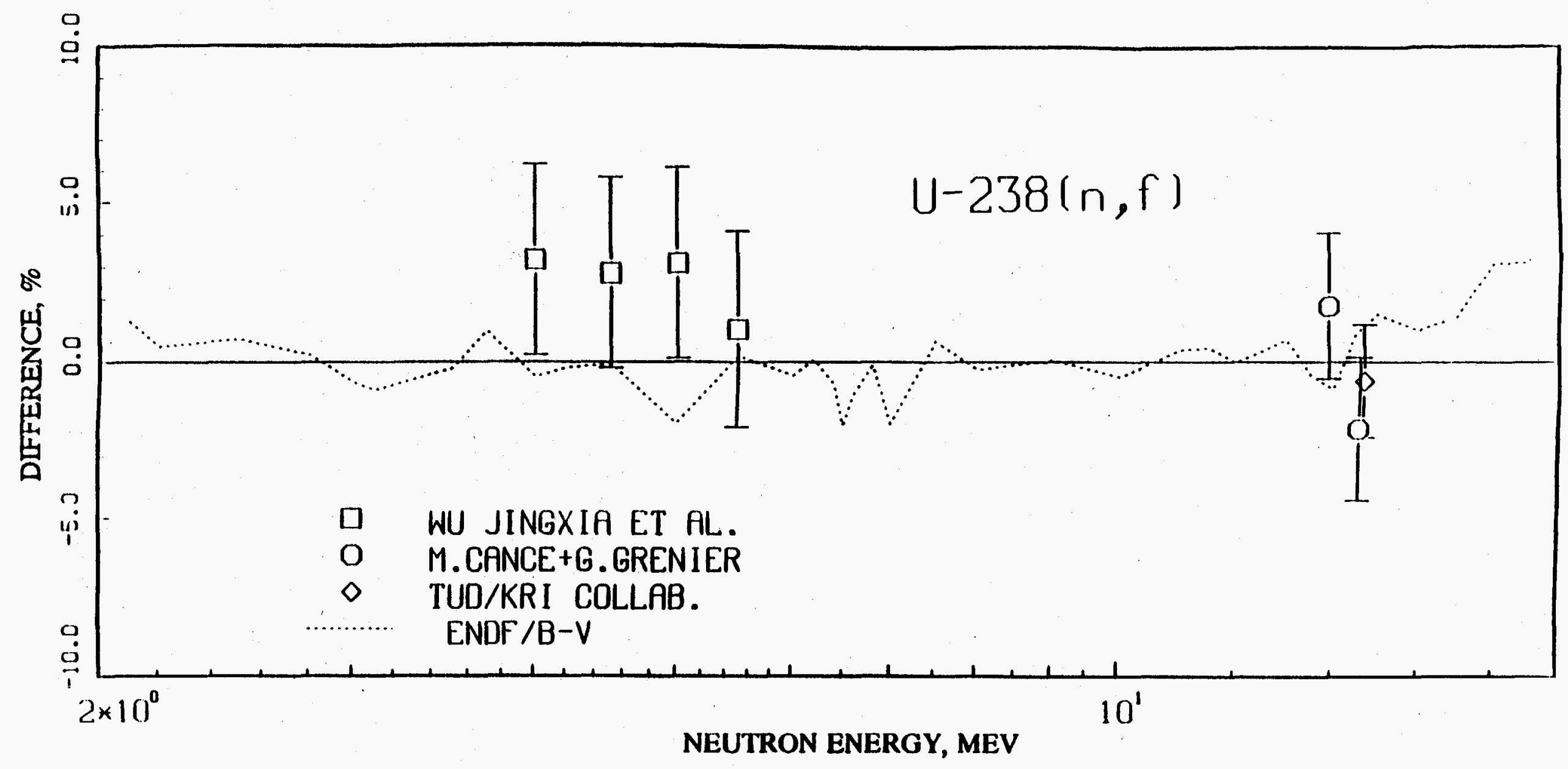

Fig. 17 Some Data on ${ }^{238} \mathrm{U}(\mathrm{n}, \mathrm{f})$ Used in the Global Evaluation. Shown is the Difference to the Result (ENDF/B-VI) 


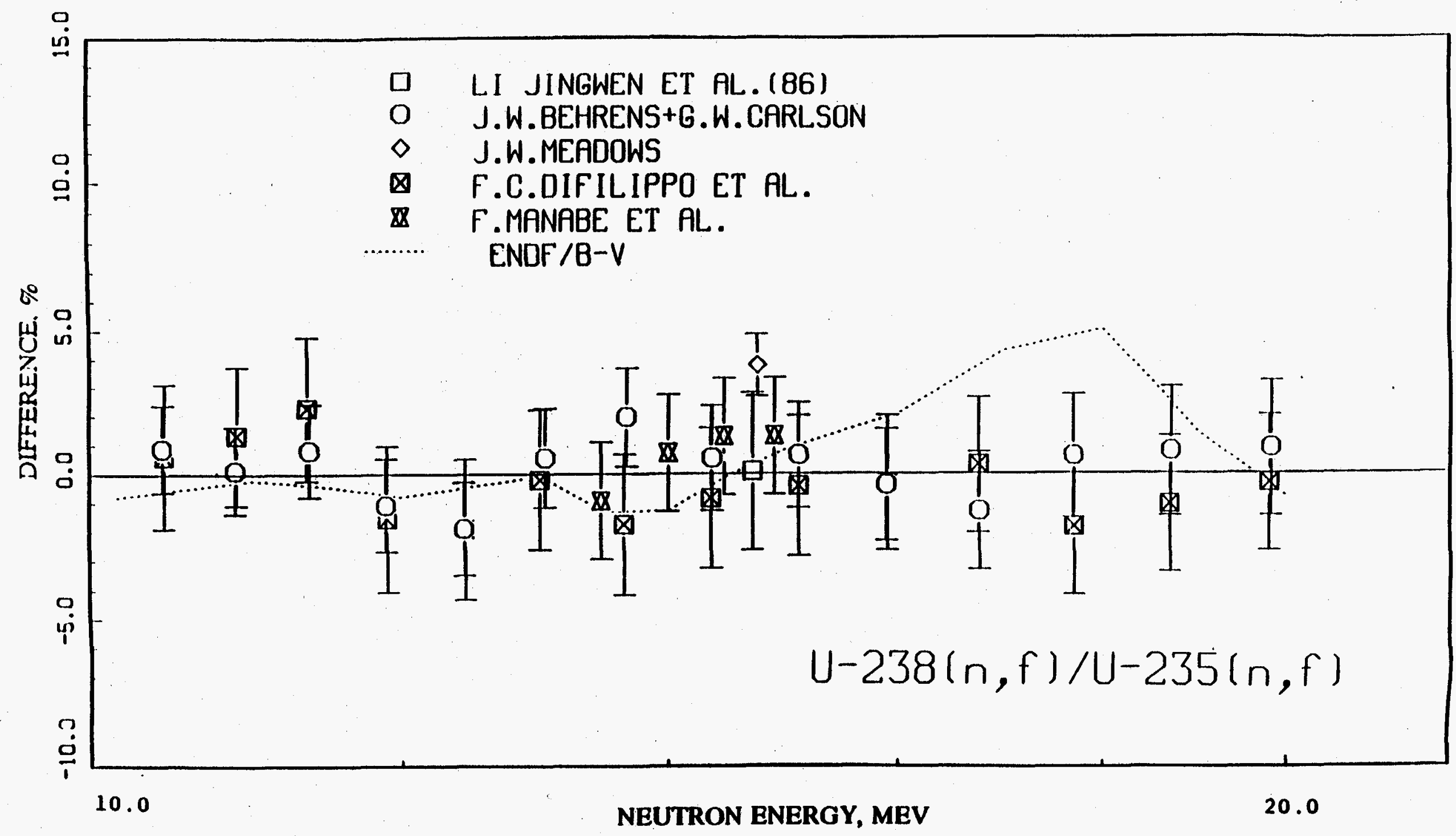

Fig. 18 Some of the Experimental Data of ${ }^{23} U(n, f) / 235 U(n, f)$ Used in the Global Evaluation. Shown is the Difference to the Evaluation Result (ENDF/B-VI) 


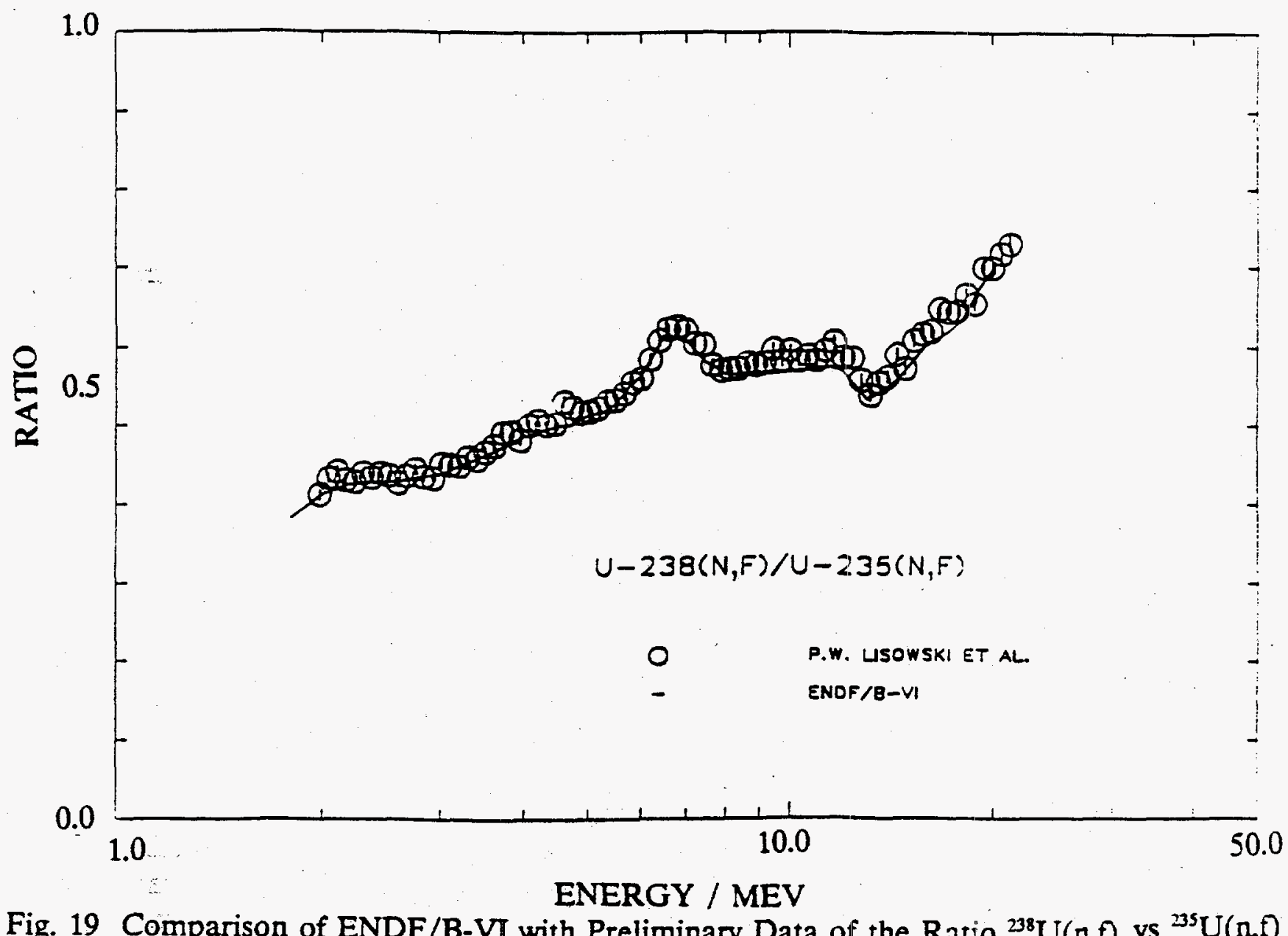

Fig. 19 Comparison of ENDF/B-VI with Preliminary Data of the Ratio ${ }^{238} \mathrm{U}(\mathrm{n}, \mathrm{f})$ vs ${ }^{235} \mathrm{U}(\mathrm{n}, \mathrm{f})$ 
IV.

\section{Summary and Conclusions}

The evaluation of the standards and other important cross sections for ENDF/BVI was carried out in three distinct steps: A generalized least-squares fit of various correlated cross section data, an R-matrix fit of the light element data, and a combination procedure involving the results from the two prior steps. The results from this global evaluation (ENDF/B-VI) stand up very well in the comparison with new experimental data which have become available after the completion of ENDF/B-VI. Specifically, the ${ }^{233} \mathrm{U}(\mathrm{n}, \mathrm{f})$ appears to be well confirmed by numerous measurements at all energies below $15 \mathrm{MeV}$. The same applies for the ${ }^{238} \mathrm{U}(\mathrm{n}, \gamma)$ cross section over the energy range of the evaluation. It is interesting that the new measurements confirm the low values of the evaluation, as most of the older data are higher than ENDF/B-VI.

A few possible problems are indicated by the new or revised data. The differential $H(n, p)$ cross section around $14 \mathrm{MeV}$ which was not part of the global evaluation is in conflict with new direct and indirect (via ${ }^{235} U(n, f)$ ) measurements. A new measurement of the ${ }^{10} \mathrm{~B}\left(\mathrm{n}, \alpha_{0}\right) /{ }^{10} \mathrm{~B}\left(\mathrm{n}, \alpha_{1}\right)$ ratio is in conflict with the ENDF/BVI ratio above $100 \mathrm{keV}$, whereas a new shape measurement of ${ }^{10} \mathrm{~B}(\mathrm{n}, \alpha \gamma)$ agrees very well with ENDF/B-VI, and the sum of ${ }^{10} \mathrm{~B}\left(\mathrm{n}, \alpha_{0}\right)+{ }^{10} \mathrm{~B}\left(\mathrm{n}, \alpha_{1}\right)$ of the evaluation reduces the $C / E$ discrepancy observed for integral fast reactor quantities. The ${ }^{10} B$ + $\mathrm{n}$ data base appears still to be inconsistent. New and revised data suggest higher cross sections for ${ }^{197} \mathrm{Au}(\mathrm{n}, \gamma)$ below the inelastic cusp at $\sim 270 \mathrm{keV}$ by $\sim 8 \%$ for a limited energy range of $\sim 70 \mathrm{keV}$. At all other energies the data confirm the evaluation. Higher cross sections are suggested by new (preliminary) and revised cross section data for ${ }^{235} \mathrm{U}(\mathrm{n}, \mathrm{f})$ above $15 \mathrm{MeV}$ where the evaluation was based on discrepant data. The greatest problem is present in the ${ }^{238} \mathrm{U}(\mathrm{n}, \mathrm{f})$ cross section for which new data ${ }^{38,45}$ are $2-5 \%$ higher but new ratio data ${ }^{52-54}$ are inconclusive.

Most of the new data have uncertainties which are much larger than the uncertainties of the evaluation result or are in fair agreement with the latter. Therefore, inclusion of the new data would have only a minor impact on the evaluation result. A possible exception is the ${ }^{235} \mathrm{U}(\mathrm{n}, \mathrm{f})$ cross section above $15 \mathrm{MeV}$. 
1 D. C. Dodder and G. M. Hale, private communication to CSEWG (Oct. 1987). Also see Ref. 14.

2 G. M. Hale, private communication to CSEWG (October 1987); see also Ref. 14.

3 C. Y. Fu, Nuch Sci. Eng., 106, 494 (1990).

4 W. P. Poenitz, J. Nucl. Energy, A/B 20, 825 (1966).

5 W. P. Poenitz, Proc. Conf. on Nuclear Data Evaluation Methods and Procedures, BNL Report BNL-NCS-51363, Vol I, p. 249 (1981).

6 R. W. Peelle, private communication to W. P. Poenitz (1981), see Appendix C of Ref. 14.

7 D. B. Gayther and B. H. Patrick, Proc. LAEA Consultant's Meeting on the ${ }^{235} U$ Fast-Neutron Fission Cross Section, and The ${ }^{252} \mathrm{Cf}$ Fission Neutron Spectrum, Smolenice, 28 March - 1 April, 1983, INDC(NDS)-146, p. 97.

8 V. G. Pronyaev et al., Proc. LAEA Consultant's Meeting on the ${ }^{235} U$ Fast-Neutron Fission Cross Section, and The ${ }^{252} C f$ Fission Neutron Spectrum, Smolenice, 28 March - 1 April, 1983, INDC(NDS)-146, p. 107.

9 W. P. Poenitz, Proc. Advisory Group Meeting on Nuclear Standard Reference Data, Geel, 12-16 Nov. 1984, LAEA TECDOC-335, p. 112.

10 A. D. Carlson, Progr. Nucl. Energy, 13, 79 (1984).

11 W. P. Poenitz, Proc. Topical Meeting on Reactor Physics and Shielding, ANS, Chicago, Sept. 1984, Vol II, p. 529.

12 A. D. Carison et al., Proc. Conf. Nuclear Data for Basic and Applied Science, Santa Fe, 13-17 May 1985, Vol 2, p. 1429; also as Radiat. Eff. 96,87 (1986).

13 R. Peelle and H. Condé, Proc. Conf. Nuclear Data for Science and Technology, Mito, Japan, May 30 - June 3, 1988, p. 1005.

14 A. D. Carlson et al., The ENDF/B-VI Neutron Cross Section Measurement Standards, ENDF-351, to be published (1992).

15 E. J. Axton, Central Bureau for Nuclear Measurements, GE/PH101/86; also private communication (1986).

16 G. M. Hale, Proc. Symp. on Neutron Standards and Applicarions, NBS Spec. Publ. 493, 30 (1977).

17 J. C. Hopkins and G. Breit, Nuch Data, A9, 137 (1971).

18 H. G. Priesmeyer et al., Proc. Conf. Nuclear Data for Basic and Applied Science, Santa Fe, 13-17 May 1985, Vol 2, p. 1463; see also NEANDC(E)-272U.

19 T. B. Ryves and P. Kolkowski, Ann. Nucl. Energy, 17, 657 (1990).

20 S. B. Borzakov et al., Sov. J. Nuch Phys., 35, 307 (1982).

$21 \mathrm{~J}$. Schmiedmayer and M. C. Moxon, Proc. Conf. Nuclear Data for Science and Technology, Mito, Japan, May 30 - June 3, 1988, p. 165.

22 A. L. Kirilyuk et al., Proc. of the Int. Conf. on Neutron Physics, Kiev, 1987, Vol. 2 , p. 298.

23 R. A. Schrack et al., Nucl. Sci Eng., to be published (1992).

24 L. W. Weston and J. H. Todd, Nucl. Sci. Eng., 109, 113 (1991). 
25 M. D. Olson and R. W. Kavanagh, Phys. Rev., C30, 1375 (1984).

26 W. P. Poenitz and P. J. Collins, Proc. NEACRP Spec. Meeting on Applications of Critical Experiments and Operating Data to Core Design via Formal Methods of Cross Section Data Adjustments, Jackson Hole, WY, Sept. 1988, Report NEACRP-L-307, p. 97.

27 S. Sakamoto et al., NucL Sci. Eng., 109, 215 (1991).

28 J. C. Robertson et al., J. Nucl Energy, 23, 205 (1969).

29 A. N. Davletshin et al, Sov. J. Atomic Energy, 65, 913 (1988).

30 L. E. Kazakov et al, Yad. Konstanty, 44, 85 (1990).

31 V. L. Demekhin et al, Proc. 36th All Union Conf. on Nuch, Kharkov, p. 94 (1986).

32 E. Quang and G. Knoll, Nucl Sci Eng., 110, 282 (1991).

$33 \mathrm{~K}$. Kobayashi et al., Proc. Conf. on Nuclear Data for Science and Technology, Jülich, (1992) p. 65.

34 Yu. V. Adamchuk et al, Sov. J. Atomix Energy, 65, 920 (1989).

35 N. N. Buleeva et al, Sov. J. Atomic Energy, 65, 930 (1989).

36 F. H. Froehner, Nucl Sci Eng., 103, 119 (1989).

37 A. D. Carlson et al., NucL Sci. Eng., to be published (1992).

$38 \mathrm{~K}$. Merla et al., Proc. Conf. on Nuclear Data for Science and Technology, Jülich, (1992) p. 510.

39 V. N. Dushin et al., Proc. LAEA Consultant's Meeting on the ${ }^{235} U$ Fast-Neutron Fission Cross Section, and The ${ }^{252}$ Cf Fission Neutron Spectrum, Smolenice, 28 March-1 April, 1983, p. 53.

40 W. P. Poenitz and J. W. Meadows, Proc. LAEA Consultant's Meeting on the ${ }^{235} U$ Fast-Neutron Fission Cross Section, and The ${ }^{252}$ Cf Fission Neutron Spectrum, Smolenice, 28 March-1 April, 1983, p. 27.

41 A. D. Carlson et al., Proc. Spec. Meeting on Neutron Cross Section Standards for the Energy Region above $20 \mathrm{MeV}$, Uppsala, May 1991, Report NEANDC-305, "U", p. 165.

42 P. W. Lisowski et al., Proc. Spec. Meeting on Neutron Cross Section Standards for the Energy Region above $20 \mathrm{MeV}$, Uppsala, May 1991, Report NEANDC-305, "U", p. 177; see also p. 165.

43 R. G. Johnson et al., Nucl Sci. Eng., to be published (1992).

44 T. Iwasaki et al., Proc. Conf. Nuclear Data for Science and Technology, Mito, Japan, May 30 - June 3, 1988, p. 87.

45 G. Winkler et al., Proc. Conf. on Nuclear Data for Science and Technology, Jülich, (1992) p. 514.

46 N. Kocherov and H. Vonach, Int. Reactor Dosimetry File (IRDF-90): Status and Testing, Proc. 7th ASTM Symp. on Reactor Dosimetry, 27-31 August 1990, Strasbourg, France.

47 Wu Jingxia et al., Chinese J. Nuch Phys., 5, 150 (1983).

48 J. W. Meadows, Argonne National Lab. Report ANL/NDM-97 (1986).

49 W. P. Poenitz, private communication to A. Carlson, NIST; G. Hale, LANL, and R. Peelle, ORNL, July 30, 1987. 
50 J. W. Behrens and G. W. Carison, Nuch. Sci. Eng., 63, 250 (1977).

51 F. C. Difilippo et al., Nuch. Sci. Eng., 68, 43 (1978).

52 P. W. Lisowski et al., private communication (1992).

53 V. A. Formichev et al, Proc. Conf. on Nuclear Data, Juelich 1991, p. 534.

54 M. Baba et al, J. Nucl. Sci \& Techn, 26, 11 (1989).

55 J. Voinier, private communication to BNL (1991). 